Escuela de

Postgrado de

Marketing

Internacional

\title{
Concepción de un plan de negocios para la creación de una agencia de representación de nuevos músicos. Modelo de aplicación basado en el género Pop-Rock.
}

Trabajo Científico libre para la obtención del grado de Magíster en

Marketing Internacional de la Escuela de Postgrado de Marketing Internacional -Facultad de Ciencias Económicas

- Universidad Nacional de La Plata -

Director de Tesis

Prof. Mag. Federico Del Giorgio Solfa
Presentado por

María José Ávalos Ledesma

Calle $24 \mathrm{~N}^{\circ} 1925$ 1/2

(1900) La Plata

Fecha de entrega: 14-03-2017 


\section{PRÓLOGO Y AGRADECIMIENTOS}

Como requerimiento para la obtención del título de Master en Marketing Internacional y luego de haber culminado todas las asignaturas, surge el último requisito que es la realización de la tesina. La misma que se realizó al haber encontrado una idea y haberla plasmado en un plan de negocio siguiendo los parámetros académicos solicitados por la EPMI.

Al realizar un plan de negocio a partir de la idea de creación de una agencia de representación de artistas musicales, se analizaron los distintos factores que intervienen en el mismo, para de esta manera evaluar si la idea de negocio es factible o no y así mismo aplicar los conocimiento adquiridos en la maestría al emplearlos en un caso aplicativo que es el de IOSSA, un músico italiano con gran potencial.

El hecho de haber conocido a Angelo lossa en un aspecto personal, fue de gran ayuda y también funcionó como inspiración para poder realizar este plan de negocio, ya que generó un interés profesional en el área de representación de artistas, por lo que se buscó la forma de aplicarlo para la tesina.

Adicionalmente, quiero agradecer a mi director de tesis quién fue un guía imprescindible en este proyecto y me ha ayudado a culminar esta etapa tan necesaria de la Maestría. También a mi familia por el apoyo incondicional que recibí para poder realizar esta meta personal a pesar de la distancia que en algunos momentos se sintió más que en otros, siempre estuvieron dándome la fuerza para poder seguir adelante. Finalmente pero no menos importante agradezco a Martín, quién vivió este proceso acompañándome y apoyándome en todas mis experiencias en Argentina y que fue y es un gran pilar para mí. Asimismo su familia quién me hizo sentir que tengo una segunda familia en este país. 


\section{TABLA DE CONTENIDO}

Capítulo I. Introducción Metodológica ......................................................................... 8

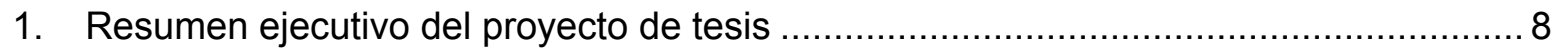

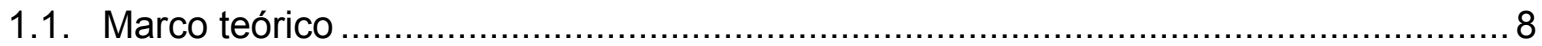

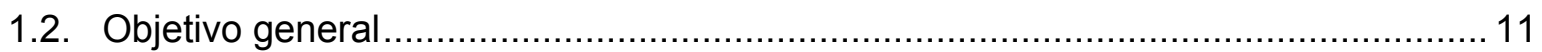

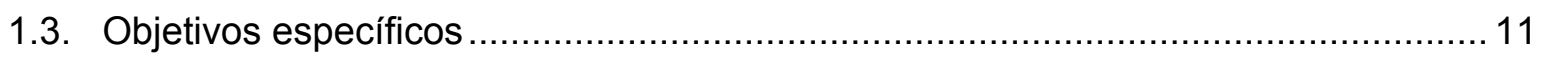

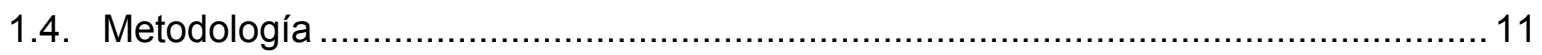

Capítulo II. Situación General del Mercado................................................................. 14

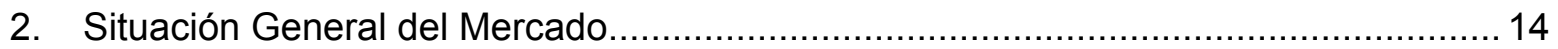

2.1. Análisis e investigación del mercado para músicos globales independientes del

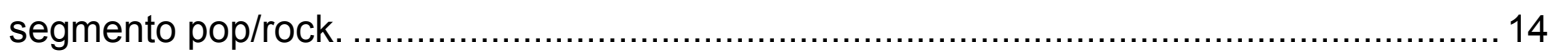

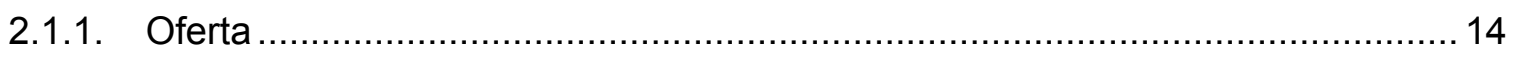

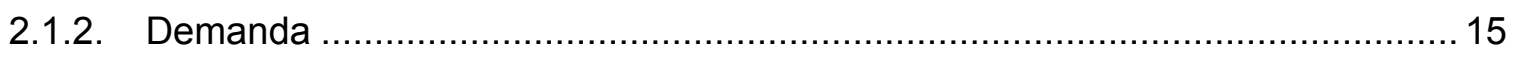

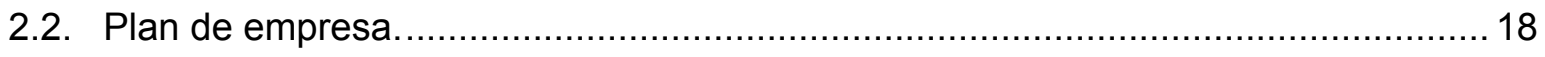

2.2.1. Visión y misión de la empresa .............................................................. 18

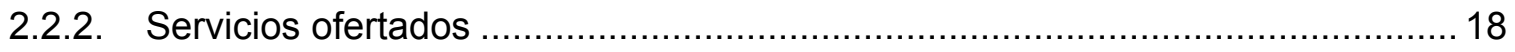

2.2.3. Constitución de la empresa. Marco legal ................................................... 19

2.2.4. Trámites legales para la constitución de la empresa ..................................... 20

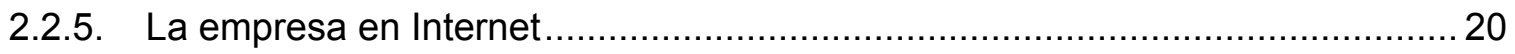

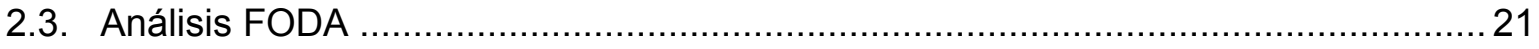

Capítulo III. Estudio de la Competencia de la Agencia de Representación.................... 23

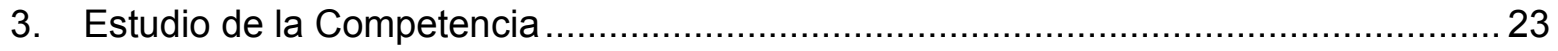

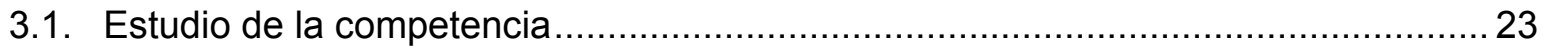

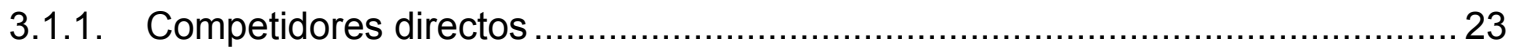

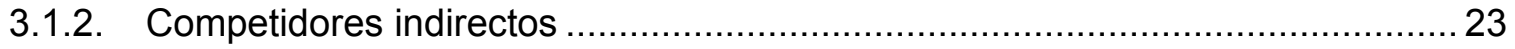

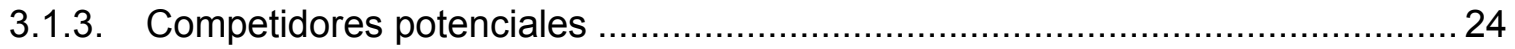

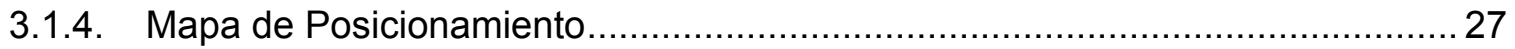

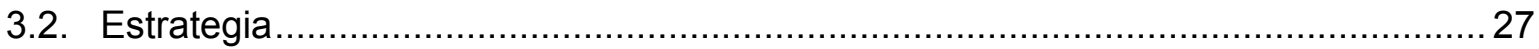

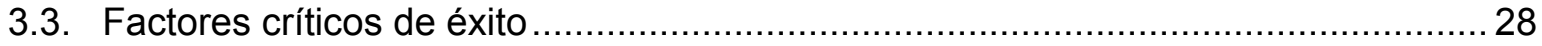

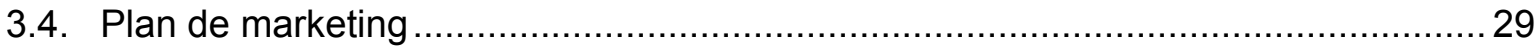

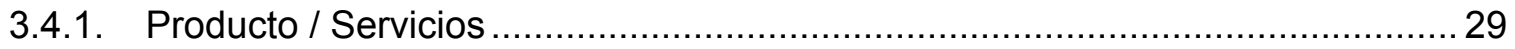

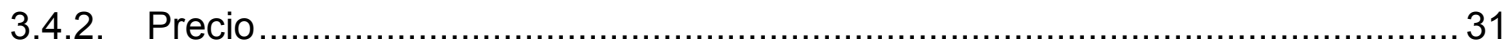

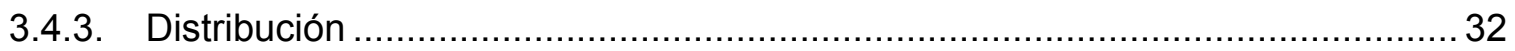




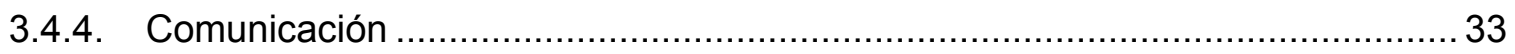

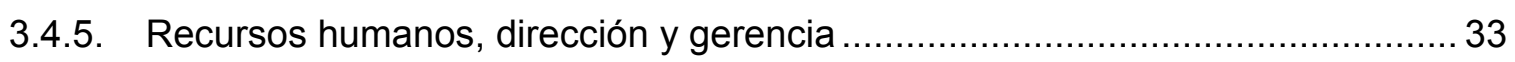

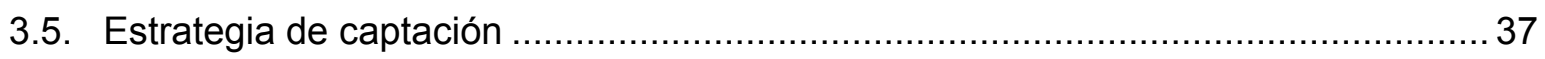

Capítulo IV. Análisis de factibilidad del plan de negocios. .............................................38

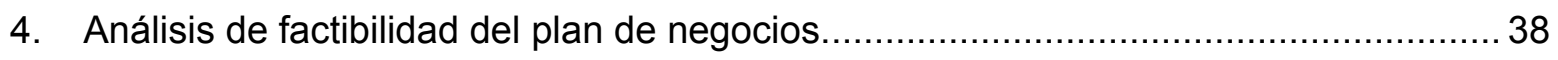

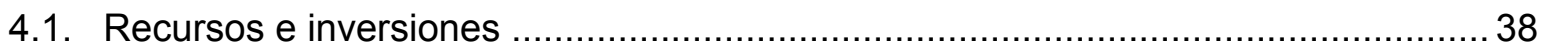

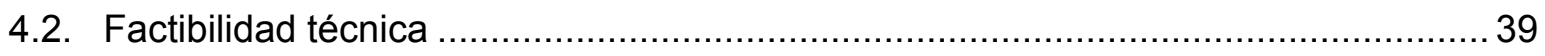

4.3. Factibilidad económica …………............................................................... 40

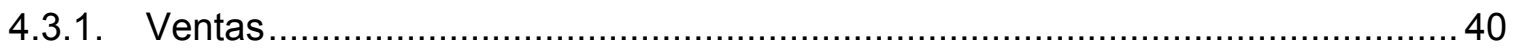

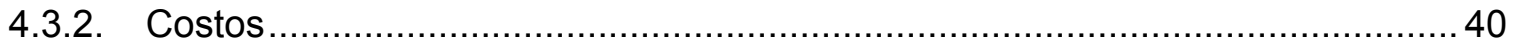

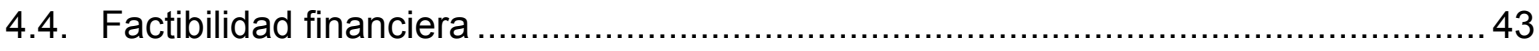

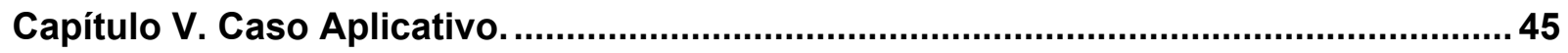

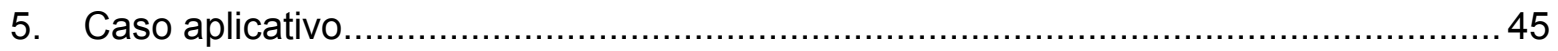

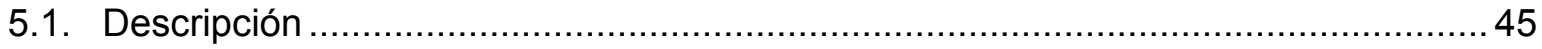

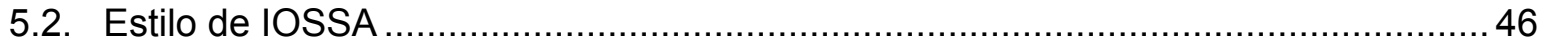

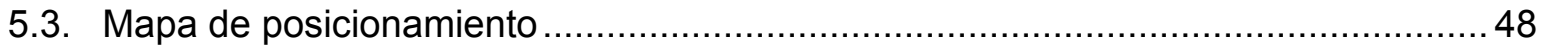

5.4. Estrategias de Marketing del Cantautor................................................................ 50

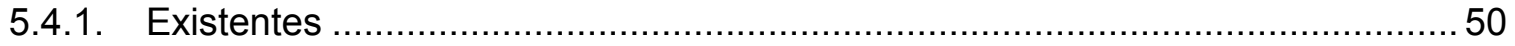

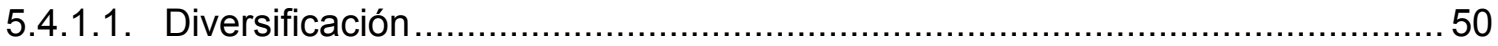

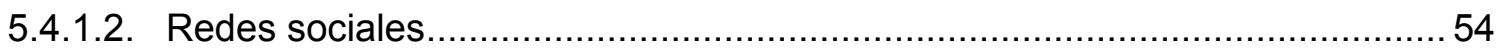

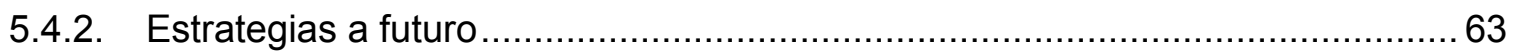

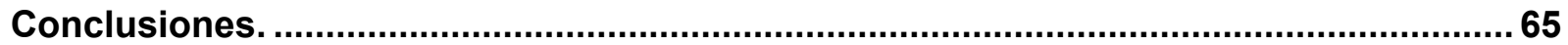

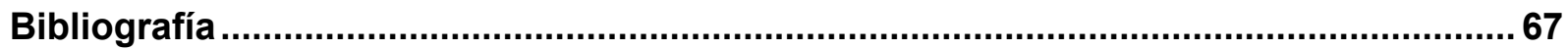




\section{LISTA DE FIGURAS}

Figura 1.- Ventas mundiales de música grabada.

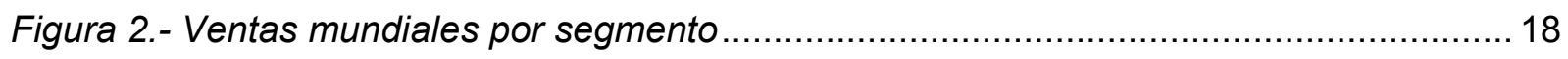

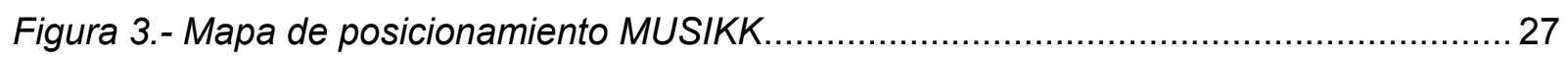

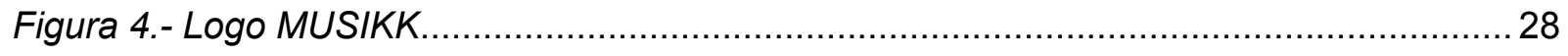

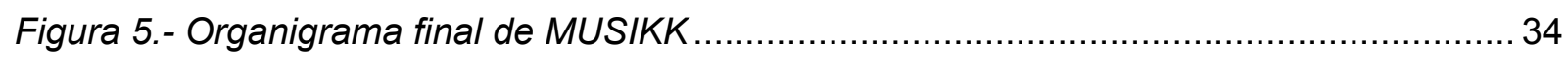

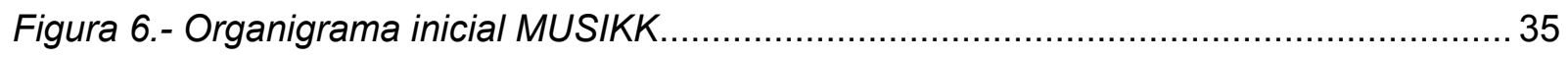

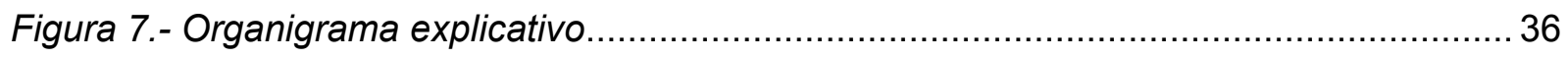

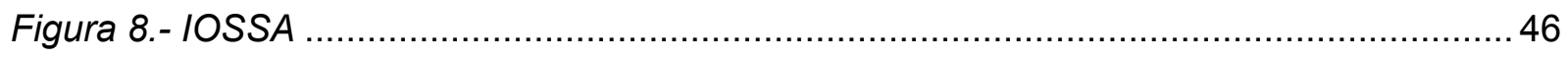

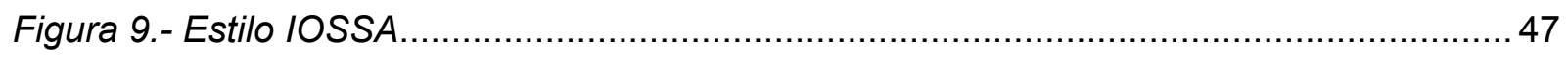

Figura 10.- Mapa de posicionamiento costo - idoneidad IOSSA …..................................... 48

Figura 11.- Mapa de posicionamiento estilos musicales - mercado IOSSA ......................... 49

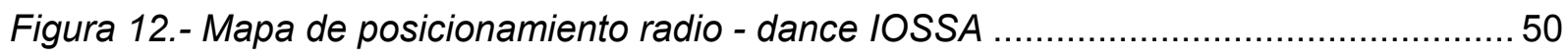

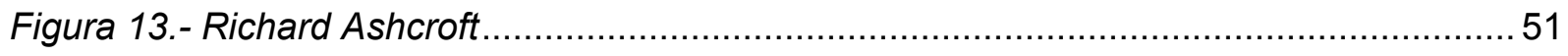

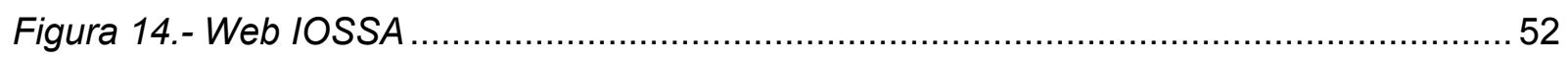

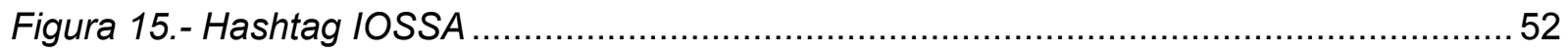

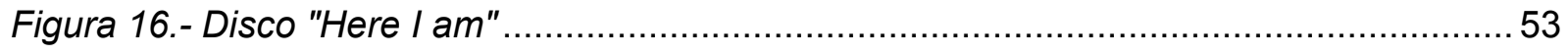

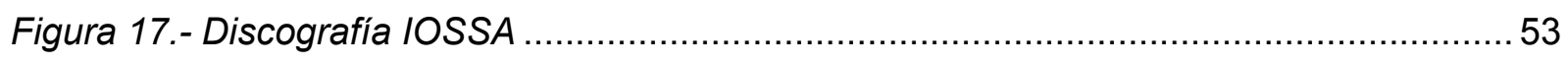

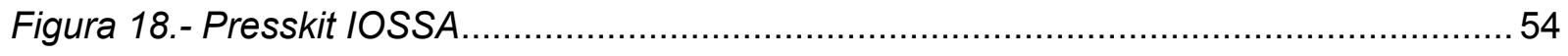

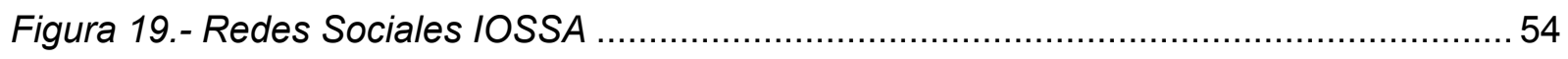

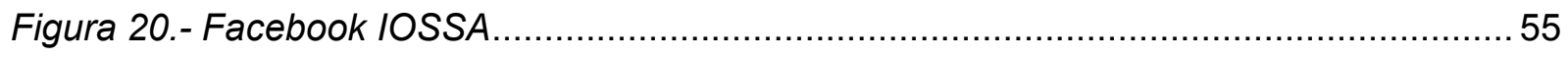

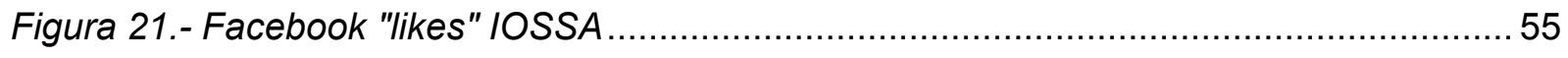

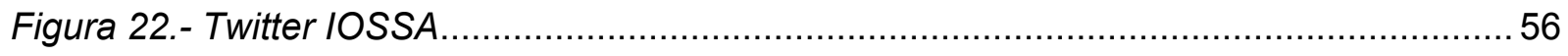




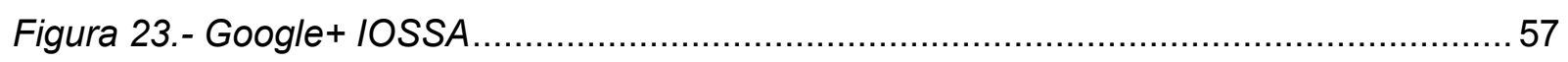

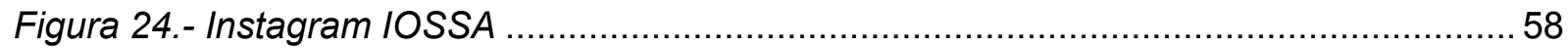

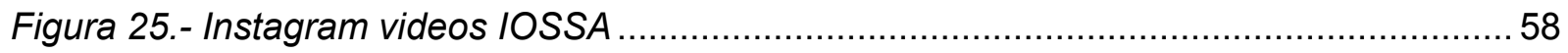

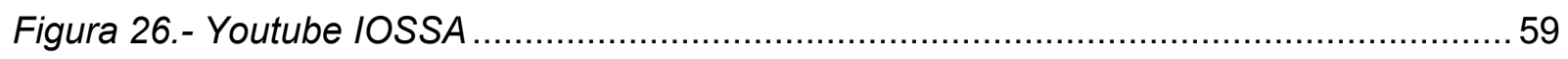

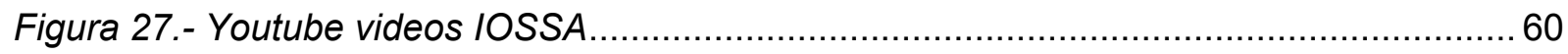

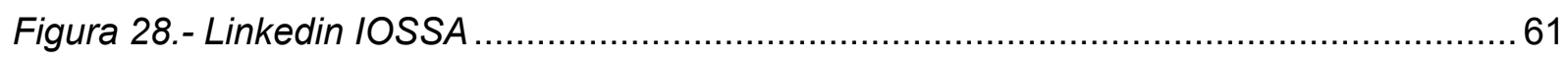

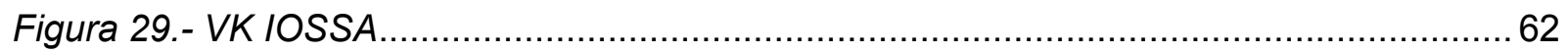

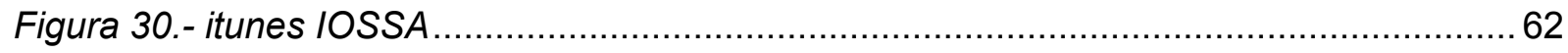

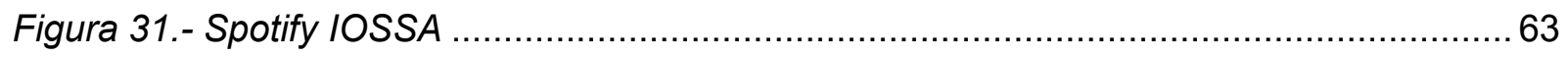

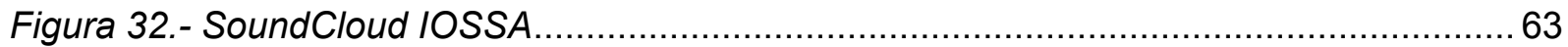




\section{LISTA DE TABLAS}

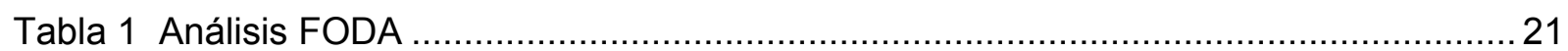

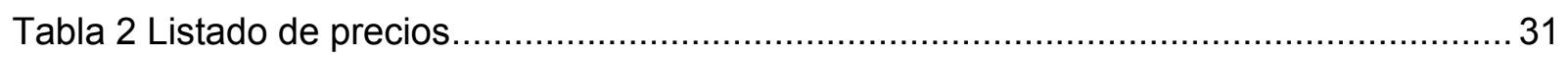

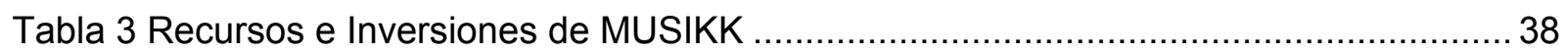

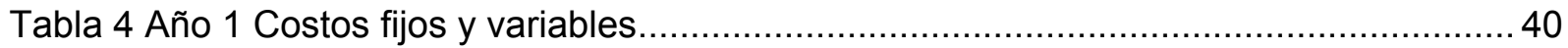

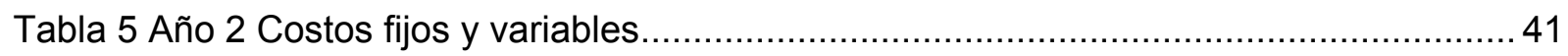

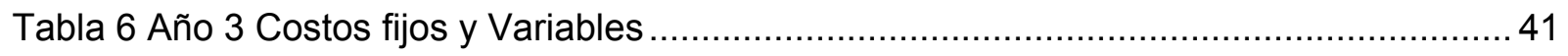

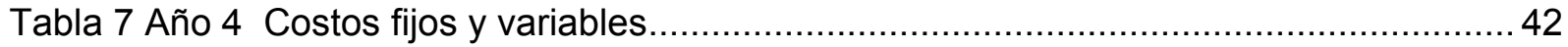

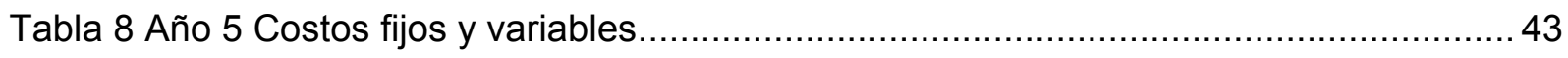

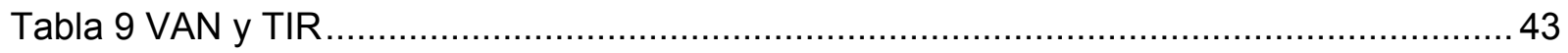





\section{Capítulo I. Introducción Metodológica}

1. Resumen ejecutivo del proyecto de tesis

\subsection{Marco teórico}

Un Plan de Negocios internacional es un documento empresario fundamental, tanto para una gran compañía como para una pyme ${ }^{1}$ ya que es un compilado de información que sirve como guía para la dirección de una empresa con el fin de evaluar el negocio ${ }^{2}$, en este caso se evaluará la concepción de una Agencia de Representación internacional de artistas musicales.

El plan de negocios será también una herramienta de trabajo y reflexión debido a que durante su elaboración se estimará la factibilidad de la idea, se buscarán alternativas y se propondrán cursos de acción. Por lo tanto servirá como punto de partida para el desarrollo de la concepción de la Agencia de Representación de artistas musicales y mediante el cual se evaluará la calidad del negocio ${ }^{3}$.

En el proceso de realización del Plan de Negocios se interpretará la actividad empresarial, se calcularán los resultados que se obtendrán y se definirán las variables involucradas en el proyecto para asignar óptimamente los recursos y ponerlo en marcha ${ }^{4}$.

Entonces, la información que se ha considerado necesaria presentar va desde la situación general del mercado, para luego realizar un estudio de la competencia y finalmente realizar un análisis de factibilidad del plan de negocios internacional. Así el proyecto pueda ser

\footnotetext{
${ }^{1}$ Terragno, L. D., \& Lecuona, M. (1999). Cómo armar un plan de negocios. Capital Federal, Argentina: Editorial Coyuntura SAC.

${ }^{2}$ Terragno, L. D., \& Lecuona, M. (1999). Cómo armar un plan de negocios.Capital Federal, Argentina: Editorial Coyuntura SAC.

${ }^{3}$ Álvaro, F. V. (2007). Aprender a elaborar un plan de negocios (Paidós ed.). Barcelona.

${ }^{4}$ Álvaro, F. V. (2007). Aprender a elaborar un plan de negocios (Paidós ed.). Barcelona.
} 
entendido, aceptado y también podría ser útil para solicitar créditos o buscar inversores o socios si el caso lo amerite ${ }^{5}$.

El plan de negocios internacional servirá también para identificar ventajas y desventajas que se podrían presentar a mediano o largo plazo en la Agencia de Representación, asimismo dará los instrumentos necesarios para afrontarlas y tratar de convertirlas en fortalezas y oportunidades ${ }^{6}$.

La idea de una agencia de representación de artistas, es contar con las herramientas necesarias para identificar las características más representativas que lo diferencien del resto al promocionar su carrera musical por medio de estrategias tanto locales como globales pero a su vez exclusivas para cada uno ${ }^{7}$.

El desafío de la agencia de representación será, sin duda, conseguir un mayor nivel de promoción internacional con un alto grado de profesionalismo para crear también un argumento decisivo en los artistas para llegar firmar un contrato ${ }^{8}$.

Es por esta razón que, además de usar las herramientas más actuales del marketing, no se debe dejar de lado la implementación de una de sus bases como lo son las 4 P producto, precio, plaza y promoción ${ }^{9}$, las mismas que apuntarán al mercado de la oferta y en las que enfocarán las estrategias del producto, que serán preferiblemente de estandarización, es decir, un producto, muchos mercados ${ }^{10}$. Por lo que se tratarán de aplicar primero en el mercado local y después en el mercado global ${ }^{11}$.

En estos tiempos, de la era digital, es imprescindible para un artista compartir su talento de manera global $^{12}$, debido al alcance al que puede llegar gracias a Internet que ya tiene 3

\footnotetext{
${ }^{5}$ Terragno, L. D., \& Lecuona, M. (1999). Cómo armar un plan de negocios.Capital Federal, Argentina: Editorial Coyuntura SAC.

${ }^{6}$ Harvard Business School Publising Corporation. (2009). Plan de negocios . Santiago Chile: Impact Media Comercial S.A.

${ }^{7}$ Viejo, L. C. (2014). Plan de informes de marketing internacional.España: Ediciones Paraninfo S.A.

${ }^{8}$ Gilmore, J. H., \& Pine II, B. J. (2009). Marketing $1 \times 1$ cada cliente es un mercado. Harvard Business Review. Bogotá: Grupo Editorial Norma.

${ }^{9}$ Kotler, P., \& Amstrong, G. (Sexta Edición). Fundamento de Marketing. Ciudad de México: Pearson Educación.

${ }^{10}$ Bradley, F. Marketing Internacional 5ta Edición. Editorial Pearson - Prentice Hall.

${ }^{11}$ Lerma Kirchner, A. E., \& Márquez Castro, E. (2010). Comercio y marketing internacional. Cuarta edición. México, D.F.: Cengage Learning

${ }^{12}$ Morales, D. V. (2014). Innovación y marketing de servicios en la era digital. Madrid: Esic Editorial
} 
billones de usuarios a nivel mundial ${ }^{13}$ y ese número va en aumento cada día. A pesar de su alcance, es necesario implementar estrategias internacionales de diferenciación ${ }^{14}$ y que sean afines a cada mercado al que se quiera dirigir ${ }^{15}$.

Esto quiere decir que la agencia lo que tratará de hacer con el artista es acomodar cada elemento para maximizar su efectividad en cada mercado en el que se enfoque, buscando los cambios que se presenten para que las estrategias estén acordes a los gustos y preferencias locales ${ }^{16}$.

Para el mundo de la música un artista es la pieza principal, ya que su obra es creada gracias a su especialidad y técnica, y éstas generan dos características importantes para dar a conocer, una es a su persona como intérprete y otra su obra ${ }^{17}$. Entonces, un artista puede ser muy talentoso pero dependerá de si es o no asertivo al momento de generar negocios que lo hagan crecer profesionalmente y económicamente ${ }^{18}$.

En este análisis la música es muy importante al ser uno de los elementos principales que acompañará al artista y su promoción será en conjunto en el plan de negocios internacional.

Es por esta razón que en el modelo aplicativo tendrá los siguientes ejes de análisis dentro del plan de negocios: El primero será en el ámbito personal, se identificará en el artista que tenga determinados valores personales, su entorno familiar y su historia de vida. El segundo se establecerá la imagen del artista, es decir, su estética por ejemplo cómo sostener un peso promedio, su higiene personal, entre otras.

El tercer eje de análisis será de tipo vincular, en otras palabras de cómo se relaciona y reacciona el artista en su entorno dentro de distintos contextos. Por último habrá un cuarto eje de análisis que sería el contrato entre la Agencia de representación y el artista y también el contrato que utilizará la Agencia de representación para contrataciones de los servicios de los artistas.

\footnotetext{
${ }^{13}$ United Nations International Telecommunications Union. (2016). UN News Centre. Retrieved 21 de Julio de 2016 from Copyright United Nations:

http://www.un.org/apps/news/story.asp?NewsID=47729\#.V5VhLTm7iko

${ }^{14}$ Bradley, F. Marketing Internacional 5ta Edición. Editorial Pearson - Prentice Hall.

${ }^{15}$ King, M. (2009). Music Marketing. Boston: Berklee Press.

${ }^{16}$ Lathrop, T. (2013). This Business of global music marketing. New York: Watson - Guptill Publications.

${ }^{17}$ Colbert, F., Cuadrado, M., Nantel, J., Bilodeau, S., Rich, J. D., \& De Montoro, J. (2009). Marketing de las Artes y la Cultura. 4ta Impresión. Barcelona: Ariel S.A.

${ }^{18}$ Amaya, C. (2011). Mercadotecnia para proyectos artísticos. Createspace.
} 
En resumen, con la concepción de un plan de negocios internacional focalizado en una agencia de representación de artistas musicales, se podrá, por medio de un manual de instrucciones ${ }^{19}$, identificar la situación general del mercado en el que se desarrollará, se determinará su entorno competitivo y por último se llegará a conocer su factibilidad.

\subsection{Objetivo general}

Diseñar una agencia de representación con estrategias de marketing internacional exclusivas para facilitar el éxito de la carrera musical de profesionales en potencial crecimiento.

\subsection{Objetivos específicos}

a) Analizar la situación general del mercado para entender el entorno en el que se desarrollará la empresa.

b) Identificar la competencia que tiene la agencia para determinar qué estrategias se utilizarán.

c) Determinar los recursos que van a ser necesarios para dar impulso al proyecto demostrando su factibilidad.

\subsection{Metodología}

El relevamiento de campo que se realizará, será de tipo descriptivo, ya que se pretende medir el grado de reconocimiento internacional de una nueva Agencia de Representación de artistas musicales, por medio de indicadores tales como: la rentabilidad, la extensión y alcance de contratos y el tiempo de crecimiento.

Adicionalmente, se tomará como modelo las agencias de representación artística al tener contacto directo con representantes artísticos específicamente de músicos, por medio de entrevistas en profundidad. Mientras que la información conceptual se obtendrá de fuentes bibliográficas especializadas en planes de negocio, marketing musical y marketing internacional, ya propuestas en la bibliografía.

Por otra parte, las técnicas a utilizar serán de tipo no probabilístico con un muestreo intencional, es decir, que los elementos serán elegidos en base a juicios preestablecidos por la autora. Por lo que, una forma de determinar la clasificación del relevamiento primario es por Target objetivo, ya sea por el género musical como folklore, música tropical, rock, pop,

\footnotetext{
${ }^{19}$ Terragno, L. D., \& Lecuona, M. (1999). Cómo armar un plan de negocios. Capital Federal, Argentina: Editorial Coyuntura SAC.
} 
entre otras o por características sociales específicas como rango etáreo, ubicación geográfica, aspectos culturales, etc.

Al mismo tiempo la captación de datos será de tipo estructurado de acuerdo a los indicadores previamente establecidos, y no estructurado, debido a que las entrevistas en profundidad serán entrevistas no estructuradas. Dichos datos serán analizados al aplicar la base teórica con el modelo aplicativo propuesto y también al comprobar si se pudieron cumplir los objetivos planteados. 



\section{Capítulo II. Situación General del Mercado}

2. Situación General del Mercado.

2.1. Análisis e investigación del mercado para músicos globales independientes del segmento pop/rock.

Con el pasar de los años, la industria de la música ha generado una amplia gama de productos y servicios relacionados a la misma, que tendrán como fin acceder a distintos mercados para obtener beneficios económicos ${ }^{20}$.

En los últimos años los hábitos de consumo de la industria musical han cambiado considerablemente, debido a que nos encontramos en la era digital en la cual términos como "MP3", "streaming" y "Redes sociales" están cada vez más presentes en el lenguaje de la sociedad actual y por lo que se presencia la muerte del respaldo físico como producto masivo de consumo ${ }^{21}$.

Es por esto que se dice que el mercado global de música gravada ha ido disminuyendo considerablemente año tras año, mientras que las recaudaciones por música digital han aumentado un $9 \%$ en 2016 con respecto al $2015^{22}$.

El volumen de negocio que se genera por la explotación de música para el mercado global es difícilmente cuantificable. Pero sí se pueden medir las recaudaciones por derecho de autor en distintos formatos, principalmente en el formato digital.

\subsubsection{Oferta}

Para medir la oferta en el mundo, se deben analizar los números que manejan las grandes compañías de música que año a año invierten US $\$ 4,5$ mil millones en descubrir, desarrollar y

\footnotetext{
${ }^{20}$ Bahanovich, D., \& Collopy, D. (2009). Music experience and behaviour in young people (University of Herpordshire ed.). UK.

${ }^{21}$ Martín, D. A. (2011). Marketing Musical. Música industrial y promoción en la era digital. (C. Commons, Ed.)

${ }^{22}$ compositores, C. i. (2015). CISAC. Retrieved 31 de enero de 2017 from cisac.org: http://es.cisac.org/Sala-de-prensa/Comunicado-de-prensa/Los-derechos-mundiales-recaudados-paralos-creadores-alcanzan-un-record-de-8.600-millones-de-euros
} 
promover artistas musicales. En el 2016 la industria musical global invirtió un $27 \%$ de sus ganancias para el desarrollo de artistas a nivel mundial y a pesar de la crisis por la que están pasando, las compañías siguen invirtiendo el mismo porcentaje con el pasar de los años para el desarrollo de nuevos talentos ${ }^{23}$.

Las grandes discográficas tienen una gran inversión en la música local, sumando también un nuevo mundo de streaming, que ha provocado que los fans tengan una mayor concurrencia a actos locales, generando mayores ingresos, especialmente en países de no habla inglesa como Noruega, Holanda, Italia, Alemania y Francia que han tenido porcentajes alrededor del $55 \%$ al $90 \%$ respectivamente ${ }^{24}$.

En cuanto a América Latina, de acuerdo el reporte publicado por IFPI (International Federation of the Phonographic Industry), ha sido por quinto año consecutivo, la región con crecimientos más notorios en ingresos por venta de música grabada con un promedio de $11.8 \%$, sumado a que el segmento digital aumentó en un $44.5 \%$, superando el promedio mundial en más de cuatro veces. Mientras que los ingresos por streaming reflejaron un aumento del $80,4 \%$ siendo Brasil $(-1.8 \%)$ y Argentina (+34.8\%) los principales mercados de la región ${ }^{25}$.

Es con esta información que se puede llegar a la conclusión que en estos países existe poca oferta a comparación de la demanda que cada año está teniendo un crecimiento considerable en una gran parte de los segmentos de música, tanto digital como streaming. Por lo que es una gran oportunidad presentar nuevos talentos en estos mercados y así asegurar su éxito.

\subsubsection{Demanda}

Según información brindada por la Web Industriamusical.es, el Rock en Estados Unidos para el 2014 duplicó su popularidad en relación a la música Pop, representando así el 29\% del consumo de la música en la industria en venta de álbumes, en compra de canciones y en consumo vía streaming.

\footnotetext{
${ }^{23}$ Worlwide independent network. (2016). Investinginmusic.ifpi.org. (IFPI, Editor) Retrieved 15 de 02 de 2017 from www.ifpi.org: http://investinginmusic.ifpi.org/

${ }^{24}$ Worlwide independent network. (2016). Investinginmusic.ifpi.org. (IFPI, Editor) Retrieved 15 de 02 de 2017 from www.ifpi.org: http://investinginmusic.ifpi.org/

${ }^{25}$ Ifpi.org. (abril de 2016). Global Music Report. Retrieved 16 de 02 de 2017 from www.ifpi.org: http://www.ifpi.org/recording-industry-in-numbers.php
} 
El Rock lideró los porcentajes en ventas de discos con un 33\%, mientras que por otro lado el Pop representó un $15 \%$ de consumo. Según el portal, estos promedios fueron calculados al dividir el total de temas descargados en tracks equivalentes de álbum y número total de stream en streaming equivalente de álbum y luego añadiendo el resultado de las ventas totales de álbumes ${ }^{26}$.

Así, al decidir representar músicos que interpreten el género Rock/ Pop, aumentan las probabilidades que ese tipo de música logre llegar a una gran cantidad de personas al ser mayoría en este género a nivel mundial.

Por otro lado, se observó que según La Federación internacional de la industria Fonográfica (IFPI), al realizar un estudio en el cual expone que el $71 \%$ de consumidores de edades de 16 a 64 en el 2016, consumieron música con licencia y que los servicios pagados de audio en formato "streaming", ha ido aumentando su popularidad especialmente en aquellos de edades menores a los 25 años. Es decir, un tercio de aquellos que se encuentran entre las edades de 16 y 24 años, pagan por servicios de audio en formato streaming ${ }^{27}$.

Dicha información, da la pauta para concluir que desde un rango de edad 16 a 64 años en países con acceso libre a Internet se convierten en potenciales usuarios de nueva música presentada por artistas en crecimiento, lo cual puede generar un mayor reconocimiento con la promoción adecuada.

Por otra parte, el reporte también explica como YOUTUBE es el servicio más usado para escuchar música, ya que el $82 \%$ de sus visitantes lo usan con ese fin y muchos de ellos lo usan precisamente para escuchar música que ya conocen más que para descubrir nuevos contenidos. Por lo que también se muestra cómo las infracciones para los derechos de autor continúan siendo un inconveniente, debido a que más de un $35 \%$ de los usuarios de Internet acceden todavía a música ilegal, pero esto ha ido cambiando al ver que en el 2016 casi la mitad de usuarios de 16 a 24 años usan servicios de streamripping, lo que significa que guardan lo que estén usando vía streaming para volver a ocupar con continuidad. Mientras

\footnotetext{
${ }^{26}$ Rosal, A. N. (15 de enero de 2015). El Rock sigue siendo el género más popular en los Estados Unidos. Retrieved 2017 de Febrero de 13 from industriamusical.es: http://industriamusical.es/el-rocksigue-siendo-el-genero-mas-popular-en-los-estados-unidos/

${ }^{27}$ Ipsos Connect. (2016 de 09 de 2016). Music consumer insight report. Retrieved 14 de 02 de 2017 from ifpi.org: http://www.ifpi.org/news/IFPI-and-Ipsos-publish-Music-Consumer-Insight-Report-2016
} 
que se ha demostrado que el $82 \%$ de personas de 13 a 15 años escuchan música legal y en su mayoría están dispuestos a pagar por la misma ${ }^{28}$.

Adicionalmente, se utilizan también Smartphones que son dispositivos creados para ir sustituyendo a las computadoras en lo que a escuchar música en streaming respecta, esto ocurre en mayor porcentaje en países en vías de desarrollo y aquellos usuarios que escuchan música vía streaming, en su mayoría lo hacen en un Smartphone, entendiendo así que llevan su música preferida a todos lados.

Dichos datos dan a conocer que los servicios de música por streaming son los que más se utilizan en estos tiempos por lo que es necesario asegurar la presencia del músico que contratará los servicios de la Agencia de Representación, sabiendo ahora que el alcance del mismo es global, por lo que su promoción alcanzaría a más mercados de lo que se hubiera pensado hace algunos años.

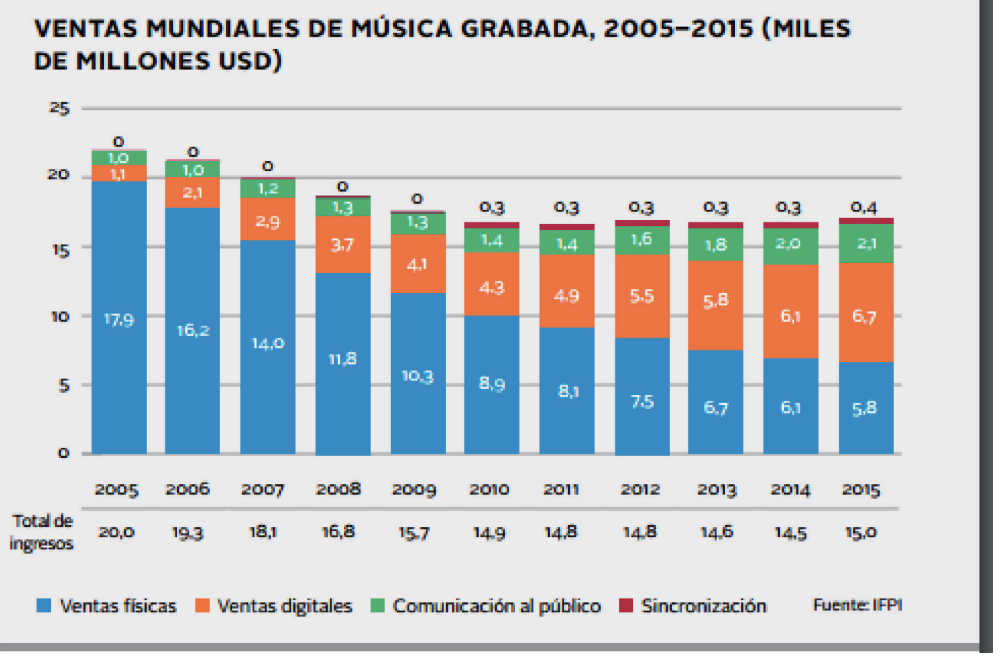

29

Figura 1.- Ventas mundiales de música grabada

\footnotetext{
${ }^{28}$ Ipsos Connect. (2016 de 09 de 2016). Music consumer insight report. Retrieved 14 de 02 de 2017 from ifpi.org: http://www.ifpi.org/news/IFPI-and-Ipsos-publish-Music-Consumer-Insight-Report-2016 ${ }_{29}$ Ifpi.org. (abril de 2016). Global Music Report. Retrieved 16 de 02 de 2017 from www.ifpi.org: http://www.ifpi.org/recording-industry-in-numbers.php
} 


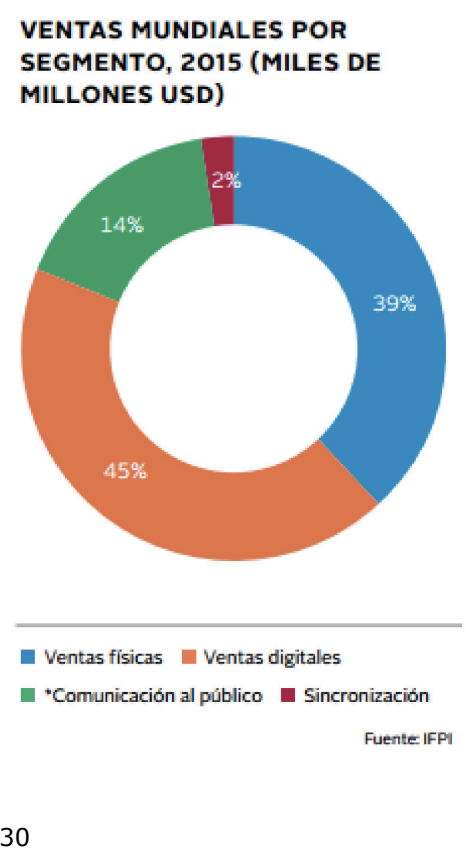

Figura 2.- Ventas mundiales por segmento

2.2. Plan de empresa.

2.2.1. Visión y misión de la empresa

\section{Visión}

Llegar a ser una empresa reconocida a nivel internacional al prestar servicios de calidad a nuestros clientes que busquen desarrollar su carrera artística para conseguir la fama deseada.

\section{Misión}

Somos una empresa que se preocupa y se encarga del crecimiento personal y profesional de músicos internacionales talentosos

\subsubsection{Servicios ofertados}

La empresa dará información detallada de los servicios que ofrece por medio de su página Web y por medio de redes sociales, asimismo para la captación de músicos que quieran desarrollar su carrera musical y llegar a ser exitosos.

\footnotetext{
${ }^{30}$ Ifpi.org. (abril de 2016). Global Music Report. Retrieved 16 de 02 de 2017 from www.ifpi.org: http://www.ifpi.org/recording-industry-in-numbers.php
} 
La agencia de representación brindará servicios que estarán descritos en el contrato que se firme con el cliente. Cada contrato va a depender del lugar de donde es originario el cliente y especificarán los servicios descritos a continuación:

1. Perfil de Artistas: Los músicos ya sean intérpretes o compositores tendrán un espacio en el sitio Web de la empresa en la cual se hará de forma de un catálogo en la que conste información bibliográfica, así como información profesional del músico en cuanto a trabajos realizados o participación de eventos, acompañado con fotografías y videos del mismo.

2. Manejo de agenda y representación de músicos buscando nuevos negocios

3. Estrategias de comunicación

4. Asesoramiento legal

5. Estrategias de marketing (marketing directo, marketing digital)

6. Participación de eventos locales e internacionales.

7. Eventos sociales para interactuar con los fans.

\subsubsection{Constitución de la sociedad. Marco legal}

La constitución de la empresa es uno de los pasos que se deben realizar para empezar la actividad y para esto hay que decidir entre las distintas modalidades en las que se puede establecer la empresa y para esto se debe tomar en cuenta por los recursos económicos y financieros de quién o quiénes van a financiar el proyecto, las características del mismo así como también la relación entre socios y su relación hacia terceros.

Los tipos de personas Jurídicas que puede adoptar una empresa en Argentina son:

Empresario individual, que no tiene límite de responsabilidad. No están previstas ni la empresa individual de responsabilidad limitada, ni las sociedades unipersonales, que han sido incluidas en los proyectos de reformas de Ley -LSC- ${ }^{31}$.

También se encuentran las formas asociativas que se dividen en civiles y comerciales. En las civiles se encuentran las sociedades Civiles, Asociación y Fundación. Mientras que en la

\footnotetext{
${ }^{31}$ Emprendedor XXI en Argentina. (2011). Creación de empresas. Retrieved 06 de febrero de 2017
} from www.emprendedorxxi.coop: http://www.emprendedorxxi.coop/html/creacion/creacion_formas.asp 
Comerciales se encuentran las Societarias, Contractuales, Solidarias, Cooperativas y Mutuales $^{32}$.

La Agencia de Representación será una entidad con fines lucrativos, ya que realizará una actividad empresarial con el objetivo de obtener beneficios económicos. Por lo que se pensó conveniente constituirla como entidad de sociedad limitada (S.R.L.) por ser una empresa pequeña.

2.2.4. Trámites legales para la constitución de la empresa Según el portal Web Emprendedor XXI, los trámites legales para la constitución de una empresa en la República Argentina están descritos a continuación ${ }^{33}$ :

- Reserva del nombre para la sociedad.

- Redacción de Estatutos y otorgamiento de Instrumento Público de Constitución.

- Inscripción de la Sociedad en el Registro Público de Comercio.

- Inscripción en la Administración Federal de Ingresos Públicos AFIP.

- Rubricación de libros ante el Registro Público de Comercio.

- Inscripción en Organismo Provincial impositivo.

- Habilitación Municipal.

- Inscripción en organismo regulador del rubro.

- Inscripción en Administración nacional de Seguridad Social ANSES.

- Inscripciones como empleador.

\subsubsection{La empresa en Internet}

Se ha determinado que la Agencia de Representación inicialmente tenga como principal característica una gestión por medio de una plataforma digital que vendría a ser un sitio Web, la misma que para ser creada, necesita cumplir ciertos requisitos detallados a continuación:

Como primer punto se debe solicitar un registro de nombre de dominio y la marca. Dado que se trata de una empresa que estará registrada en Argentina, sería ideal registrarlo en un dominio argentino, pero para que tenga un alcance más global se pensó realizar la solicitud

\footnotetext{
${ }^{32}$ Emprendedor XXI en Argentina. (2011). Creación de empresas. Retrieved 06 de febrero de 2017 from www.emprendedorxxi.coop: http://www.emprendedorxxi.coop/html/creacion/creacion_formas.asp ${ }^{33}$ Emprendedor XXI Argentina. (2011). Poner en marcha una empresa paso a paso. Retrieved 06 de febrero de 2017 from www.emprendedorxxi.coop: http://www.emprendedorxxi.coop/html/creacion/creacion_pasos.asp
} 
de registro de nombre de dominio en Estados Unidos, esto se pensó estratégicamente, ya que al estar registrado en ese país da la seguridad de que se respetará con mayor intensidad los derechos de autor y por otro lado tendrá más alcance global.

Luego se seleccionará el proveedor de servicios de Internet con sus siglas en inglés ISP (Internet Service Provider) y también la ubicación del servidor. Seguido por el desarrollo del sitio, publicación, pruebas y revisión para posteriormente comenzar con la promoción del mismo y por último mantener el sitio y actualizarlo constantemente.

El sitio Web garantizará la protección de derechos de Autor en todas aquellas obras de tipo audiovisual creadas por la empresa, así como también protección de las producciones musicales de los artistas contratados, en su publicidad y todo aquel material que represente al artista y a la empresa.

\subsection{Análisis FODA}

Tabla 1 Análisis FODA

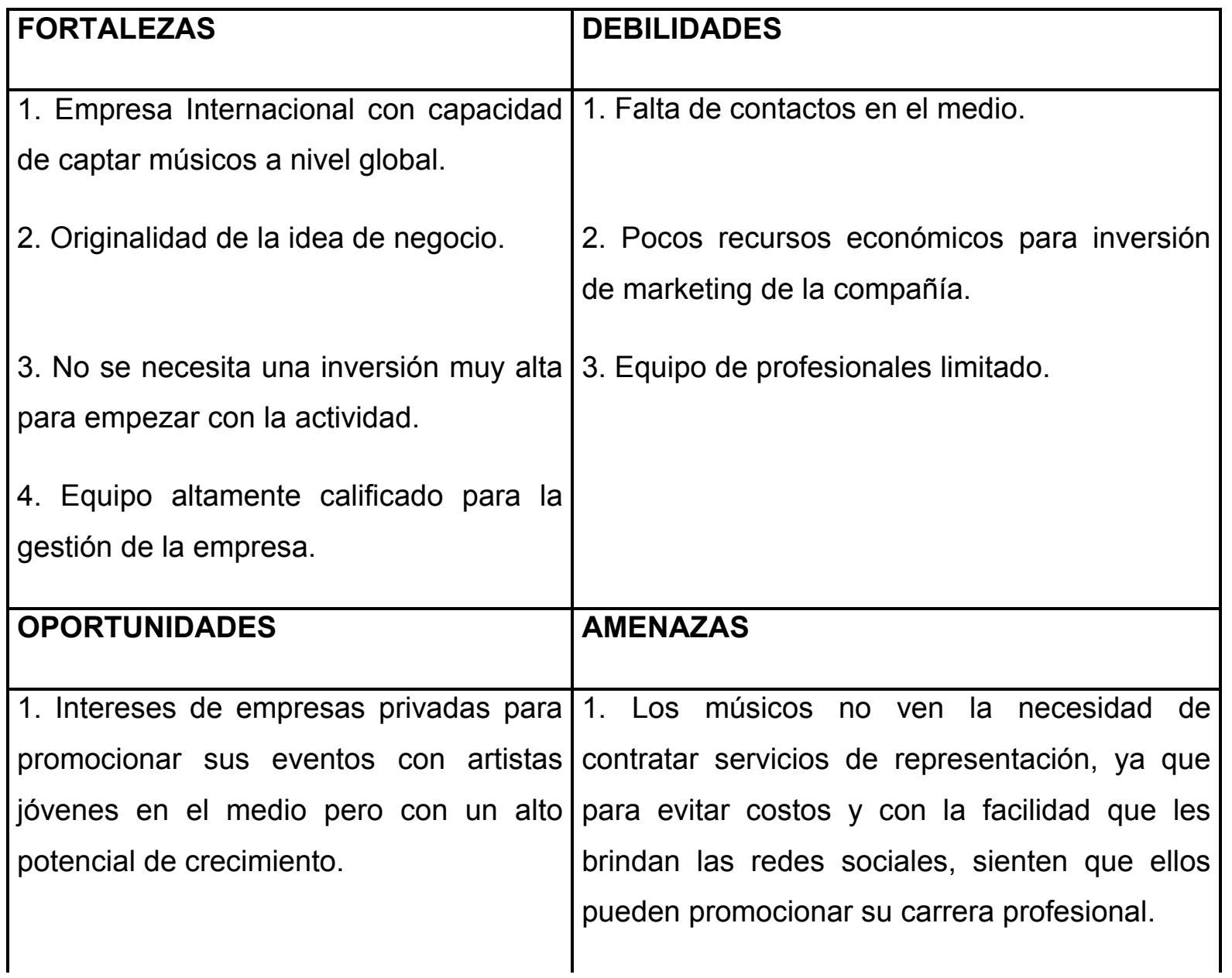




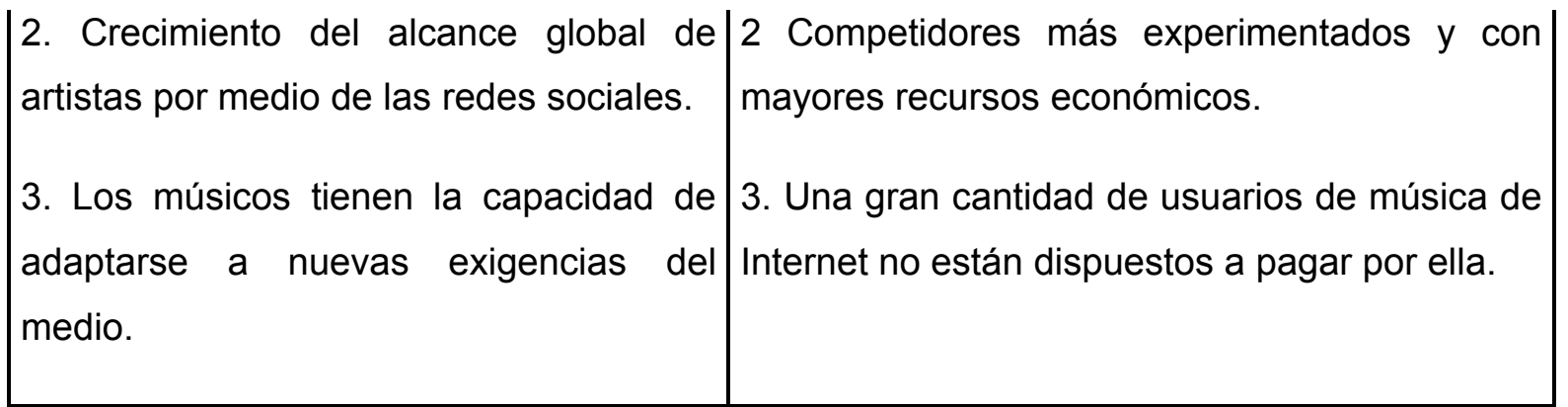

Fuente: elaboración propia.

La idea de este análisis se dio con el fin de identificar principalmente las fortalezas y potenciarlas para aprovechar las oportunidades, contrarrestar las amenazas y corregir las debilidades. 


\section{Capítulo III. Estudio de la Competencia de la Agencia de Representación.}

3. Estudio de la Competencia

3.1. Estudio de la competencia

3.1.1. Competidores directos

Se entiende como competidores directos a todos aquellos que ofrecen los mismos servicios dentro del mismo ámbito geográfico ${ }^{34}$.

En el caso de la Agencia de Representación se establecieron como competidores directos a aquellas Agencias de Representación y también a Representantes de músicos independientes en la República Argentina. Se las considera como competidores directos porque ya se encuentran establecidas y se encuentran en crecimiento y con recursos económicos para respaldar a los músicos, también al manejar una serie de contactos del medio.

\subsubsection{Competidores indirectos}

Los competidores indirectos, son aquellos que ofrecen servicios, que por sus características, pueden sustituir a los propios ${ }^{35}$.

Las dos empresas que se identificaron como competidores indirectos de la Agencia de Representación son principalmente dos Productoras musicales argentinas, que si bien se encargan de la producción musical de los artistas, también se encargan de la promoción de los mismos, pero a su vez captan todo tipo de músicos y no de un género específico. Las empresas son:

- Cassette 90 Sellos discográficos y Productora nacional, que se encarga de ofrecer servicios con mayor énfasis en la producción musical pero también en la promoción de los artistas.

\footnotetext{
${ }^{34}$ Terragno, L. D., \& Lecuona, M. (1999). Cómo armar un plan de negocios. Capital Federal, Argentina: Editorial Coyuntura SAC.

${ }^{35}$ Terragno, L. D., \& Lecuona, M. (1999). Cómo armar un plan de negocios. Capital Federal, Argentina: Editorial Coyuntura SAC.
} 
- Pampa Records producción musical para bandas y solistas. Esta empresa también se caracteriza por tener su propio estudio de grabación, por lo que se encarga desde la producción hasta la promoción de los artistas en desarrollo.

\subsubsection{Competidores potenciales}

Son aquellos que no ofrecen servicios similares en el mismo ámbito geográfico, pero por su naturaleza pueden ofrecer los mismos servicios en un futuro, teniendo en cuenta que no sólo empresas locales pueden llegar a ofrecer servicios similares, sino también empresas extranjeras que podrían ingresar en el mercado local $^{36}$.

En el caso de la Agencia de Representación, puede llegar a tener un sin número de competidores potenciales, ya que la misma trabajará con artistas internacionales en crecimiento para promoverlos globalmente. Es decir que la Agencia de Representación deberá trabajar también para competir con empresas de todas partes del mundo.

Se realizó una entrevista no estructurada a un Manager de una banda de alto reconocimiento local pero bajo reconocimiento internacional y de otro estilo musical. El nombre del manager es Paly Bilbao, representante del grupo argentino de cumbia LOS TOTORA. Paly respondió algunas preguntas que para la investigación fueron de gran ayuda para entender el trabajo de representante de músicos. A continuación la entrevista realizada el 26 de febrero del $2017^{37}$.

1. ¿Cómo hacen la captación de nuevos talentos?

No suelo hacer captación de nuevos talentos, pero sí se me presentan o me llegan propuestas de artistas nuevos o en crecimiento. Hoy por hoy, las redes sociales son sin duda una gran vidriera para que los artistas muestren su arte. Me ha pasado últimamente de conocer muchos nuevos talentos por INSTAGRAM.

2. ¿Se basan en la captación por solamente un género musical o lo hacen con músicos de otros géneros musicales?

Con 15 años ya en el medio, y más allá del género puntual en el que me suelo manejar que es la Cumbia conocida ahora como "cumbia nueva" o "cumbia cool", tuve la oportunidad de

\footnotetext{
${ }^{36}$ Terragno, L. D., \& Lecuona, M. (1999). Cómo armar un plan de negocios. Capital Federal, Argentina: Editorial Coyuntura SAC.

${ }^{37}$ Bilbao, P. (26 de Febrero de 2017). Representación de músicos en crecimiento. (M. J. Ávalos, Entrevistadora)
} 
conocer artistas de todo género. En este momento me encuentro realizando algunos trabajos con artistas de Reggaetón "blanco" o "melódico" que viene principalmente desde Colombia y está muy de moda, como es el caso de Maluma, Piso21, etc.

3. ¿En un inicio cómo hacen para promocionar a los músicos?

En este momento todo el principal canal de difusión de cualquier artista son las redes sociales. En 2001 cuando empezamos con LOS TOTORA estas no existían y el proceso que vivimos fue muy particular; al ser una banda oriunda de La Plata, ciudad de estudiantes, lo que ocurría era que lo mismos estudiantes del interior que iban a los shows, se llevaban los discos a sus pueblos o ciudades del interior. Esa fue sin dudas la forma más natural y orgánica de promoción de la banda.

4. ¿Manejan algún estándar de imagen personal para los músicos?

Va acorde a las presentaciones y a la música, es un estilo informal en general.

5. ¿Se cobró inicialmente algún valor por los servicios de representación?

En mi caso, trabajé ad honorem durante casi un año. En ese momento fue una aventura para ayudar a un grupo de amigos. Después se fue profesionalizando todo.

6. ¿Cuándo se logran conseguir contratos, ya sea para eventos o para grabación, se dividen porcentualmente las ganancias o el representante ya obtiene un valor preestablecido sin importar el valor del contrato?

En mi caso, ya tengo un porcentaje acordado con una SRL (Sociedad de Responsabilidad Limitada) que tenemos en la banda. Es fijo, pero depende de cada banda y cada Manager los acuerdos. Algunos comisionan, etc. En nuestro caso, el compromiso excede los valores. Mi función es conseguir los mejores números para todos.

7. ¿Tienen algún tipo de promoción internacional o solo local y si es local, piensan hacerlo internacionalmente?

Somos artistas de Warner Music Argentina, por ende tenemos promoción dentro y fuera del país, en Latinoamérica y hasta Miami, Europa, donde ya hemos ido 3 veces, etc.

8. ¿Su promoción es en su mayoría por Redes Sociales o por medios clásicos de publicidad? 
Es mixto. La compañía discográfica arma los planes de promoción dependiendo diferentes anuncios, shows, lanzamientos, etc. La idea es siempre estar presente en todos los medios posibles.

9. ¿Trabajan por medio de intermediarios para ganar contratos o la gestión la realizan directamente desde la agencia?

$\mathrm{Si}$, en el medio de la música hay muchos organizadores o productores o agencias que se encargan del armado de festivales, shows, etc.

10. ¿Cuántas personas trabajan en la Agencia de Representación y cuáles son sus funciones?

En nuestro caso tenemos una oficina con 4 personas que dividen tareas de diseño, imagen, redes y venta. Pero en mi caso superviso personalmente tema shows, y aparte con tantos años ya soy conocido en el medio, y la gran mayoría de gente tiene llegada a mi. 
3.1.4. Mapa de Posicionamiento

\section{Precio (+)}
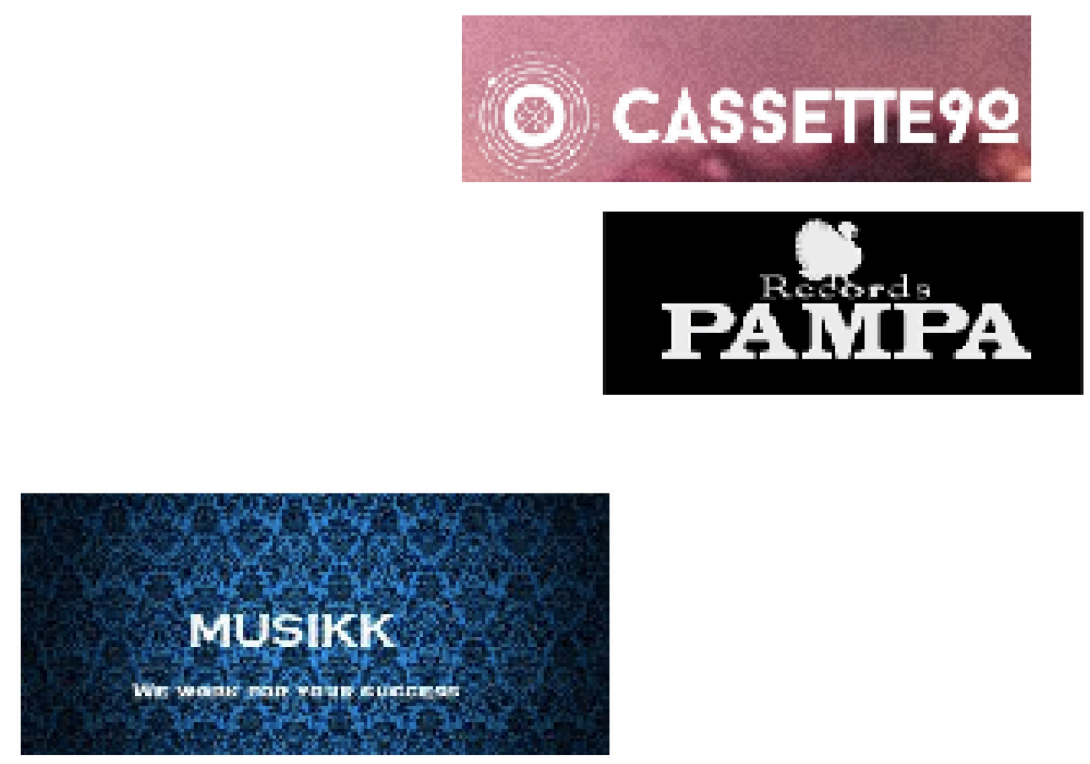

Principiante

Especialista

\section{Precio (-)}

Fuente: elaboración propia

\section{Figura 3.- Mapa de posicionamiento MUSIKK}

Según el mapa de posicionamiento, se puede observar que MUSIKK con relación a otras empresas de representación ya conocidas, maneja precios menores, esto precisamente se lo toma como una estrategia de marketing para captar más clientes. También al ser una empresa que está empezando sus funciones y al no tener tanta experiencia en el medio a comparación de dichas empresas, tratará de competir con ellas con el precio.

\subsection{Estrategia}

La Estrategia principal que se utilizará en La Agencia de Representación, es una estrategia de Diferenciación. Dicha estrategia creará valor sobre los servicios ofrecidos para que sean percibidos como únicos en los diferentes mercados en los que se trabaje. Se caracterizará principalmente por el manejo de las tecnologías tanto para la gestión como para la promoción. También, se enfocará en mantener un excelente servicio al cliente, ya sea interno y externo, y a su vez una gestión intachable con los proveedores. 
La Agencia de Representación al utilizar la estrategia de diferenciación, intenta comunicar a los potenciales clientes las estrategias exclusivas que se aplicarán como forma de promoción para el mismo, ya que se caracteriza por ser una empresa que su principal interés es el Servicio al Cliente, la gestión de su posicionamiento en el mercado y también el manejo especializado en nuevas tecnologías que garantizarán la penetración del cliente en el mercado.

Es por esta razón que la Agencia de Representación tiene como función principal crear nuevas estrategias exclusivas de marketing de acuerdo al perfil del cliente, para que las mismas representen su esencia y así el cliente se sienta a gusto de trabajar con la Agencia de Representación porque se estaría respetando su estilo musical como personal y usándolo para promocionarlo en distintos canales.

También, al manejar la estrategia de diversificación, se mantiene la opción de diversificar la oferta de los servicios que ofrece la Agencia, lo que nos garantiza que el pensamiento de la dirección está enfocado en la renovación constante ya sea de procesos de gestión o de captación de clientes. Esto hará que la idea de negocio no se estanque en un solo tipo de servicio sino que pueda adquirir nuevas ideas para el crecimiento de la empresa.

\subsection{Factores críticos de éxito}

1. Costos de Inversión: Se considera que los costos de inversión son un factor de éxito, debido a que los mismos son bajos, ya que inicialmente los únicos costos que tendrá la Agencia de Representación son para la creación del sitio Web en dónde se manejará en totalidad a la empresa. No existirán costos de infraestructura, porque en un inicio no habrá una oficina física, por los costos que representan tener una oficina.

2. Recursos humanos: En cuanto a recursos humanos se trata, habrá dos especialistas de los campos principales que manejará la Agencia, uno es marketing directo, digital y relaciones públicas y el otro es desarrollador Web. Estos dos campos garantizarán inicialmente el éxito en la gestión de la empresa. Ya que los profesionales a cargo tienen una alta capacidad de manejar estos campos.

3. Manejo de tecnologías: El manejo de tecnologías es otro factor crítico de éxito que se ha tomado, porque de acuerdo a la investigación realizada para la creación de la Agencia de Representación, se demuestra que hay una clara tendencia al uso de nuevas tecnologías, especialmente para el medio en el que se está trabajando, por lo que se trabajará inicialmente de forma digital y personal. 
4. Logística: Se toma como factor crítico de éxito, debido a que se buscará promover al artista en eventos importantes de esta manera dependerá de la capacidad de negociación y relaciones públicas del profesional para llegar a generar nuevos contratos para el cliente.

\subsection{Plan de marketing}

A continuación se realizará un Plan de Marketing para la Agencia de Representación en la cual se describirá en primera instancia el nombre de la empresa, la presentación de la marca, los servicios que ofrecerá la empresa, los precios que se manejarán, seguidos de las estrategias de distribución y también las estrategias de promoción de los servicios ofertados.

Adicionalmente se explicará cómo estará constituida el área de Recursos Humanos para llevar a cabo la gestión de La Agencia de Representación, para finalmente describir las estrategias que se utilizarán para la captación de clientes

\subsubsection{Producto / Servicios}

Para empezar, se definió el nombre para la Agencia de Representación cómo "MUSIKK" (Traducción del noruego al español para la palabra Música y se pronuncia Musíc). Con este nombre la empresa quiere expresar su esencia y su razón de ser que es promocionar Música, principalmente de aquellos músicos que tienen el talento pero no los recursos para darse a conocer.

MUSSIK, también va a representar a la marca de la Agencia de representación, la misma que se encuentra a continuación.

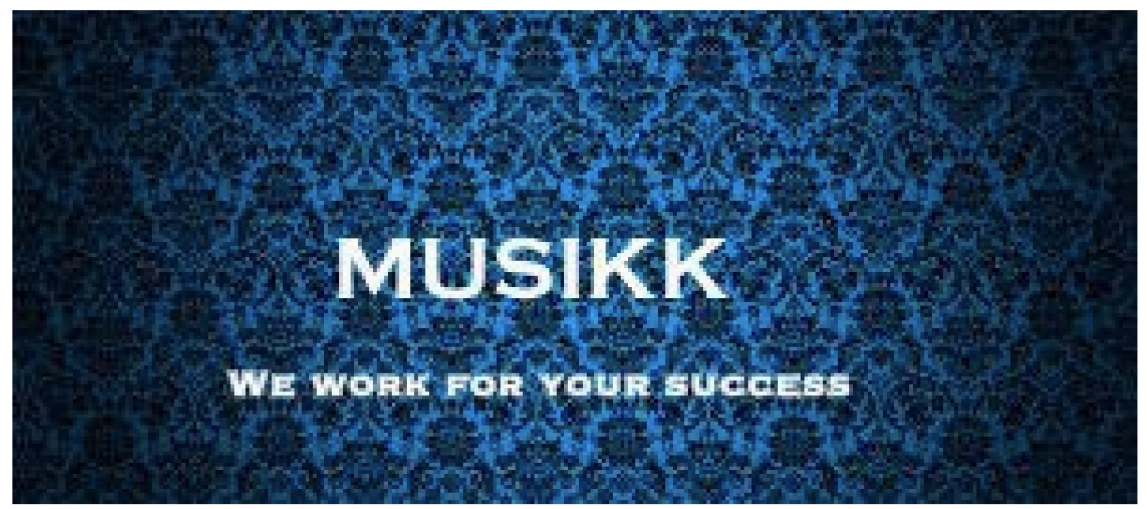

Fuente: elaboración propia

Figura 4.- Logo MUSIKK 
Con esta imagen se puede claramente notar una pared que tiene un fondo azul que va cambiando su tonalidad partiendo desde el centro con más claridad hasta los costados que se va oscureciendo con efecto sombreado. La imagen con esos colores intenta representar el género pop (azul en sus distintas tonalidades) y el género rock (con la parte más oscura).

En la mitad de la imagen se observa la palabra MUSIKK, que representa al logotipo de la empresa, el mismo que tiene una tipografía Copperplate Gothic Bold, de color blanco para que resalte la marca y a su vez nombre de la empresa. Para finalmente acompañarla con un slogan en el cual está escrito en inglés la frase "Trabajamos para tu éxito". Tratando de demostrar el compromiso que tiene la empresa con sus clientes.

Con la marca ya establecida, se apunta a trabajar en el posicionamiento de la misma al promoverla en los distintos medios en los que se encuentra el mercado meta, en este caso se toma como mercado meta a músicos intérpretes del género pop/rock que se encuentran en proceso de crecimiento.

Una vez establecido el nombre de la empresa, se establecerán los beneficios que los servicios de MUSSIK darán a los clientes potenciales, para que decidan contratar los servicios con la Agencia de Representación y tengan la confianza de que la empresa trabajará en busca de su éxito.

El primer beneficio y el principal es brindar un servicio personalizado de calidad en el cual se adapte en su totalidad en el estilo y personalidad del cliente para mejorarlo y potenciarlo y también para descubrir las debilidades del mismo para trabajar en contrarrestarlas.

Cómo segundo beneficio se estableció manejar de manera profesional todas las áreas en las que estará relacionada la presencia pública y privada del cliente.

Se garantizará su seguridad legal por medio de un contrato en el que las dos partes se vean beneficiadas tanto en promoción cómo económicamente.

Finalmente se trabajará con objetivos en tiempo para cumplirlos y alcanzar a la rentabilidad del cliente así como la de MUSIKK.

Se trabajará permanente en la comunicación del cliente utilizando distintos medios de comunicación y por medio también de pequeñas inversiones para garantizar un buen posicionamiento digital. 
Se buscará sponsors que tengan productos o servicios que estén en las mismas condiciones del cliente de MUSIKK, es decir que se encuentren en el proceso de introducción al mercado, para generar alianzas estratégicas y beneficiarse mutuamente.

\subsubsection{Precio}

El precio se pensó también como una estrategia de captación de clientes que lo veremos más adelante en el módulo de estrategias de captación. Sin embargo, MUSIKK manejará un rango de precios más económicos en relación a los de la competencia, por la falta de experiencia en el mercado, y que los clientes potenciales pueden considerar como un factor de riesgo.

Se realizará una estrategia de Precio Internacional según la demanda, es decir que con un servicio existente el precio estará sujeto a revisión, y mientras el servicio está en proceso de introducción en su ciclo de vida, el precio será diferencial, lo que quiere decir que el precio internacional estará adaptado a cada mercado.

El precio también estará especificado en el contrato de servicios prestados, y va a ser distinto para cada cliente, dependiendo del tipo de servicio que contrate y su situación personal/intelectual. De igual manera cabe recalcar, que habrá algunos servicios con precios generales para todos los clientes.

A continuación se detallará un listado de precios acorde a cada servicio que MUSSIK brindará al cliente.

Tabla 2 Listado de precios

\begin{tabular}{|l|l|}
\hline \multicolumn{2}{|c|}{ Listado de precios MUSIKK } \\
\hline Servicio & Precio en USD \\
\hline Perfil de Artista: & $\begin{array}{l}\$ 1.000-1.500 \text { pagadero en } \\
\text { única vez }\end{array}$ \\
\hline $\begin{array}{l}\text { Manejo de agenda y } \\
\text { representación de músicos } \\
\text { buscando nuevos negocios: }\end{array}$ & $\begin{array}{l}\$ 150-200 \text { pagadero cada mes } \\
\text { durante la duración del } \\
\text { contrato }\end{array}$ \\
\hline Estrategias de comunicación & $\begin{array}{l}\$ 100 \text { pagadero cada mes } \\
\text { durante la duración del } \\
\text { contrato }\end{array}$ \\
\hline
\end{tabular}




\begin{tabular}{|l|l|}
\hline Asesoramiento legal & $\begin{array}{l}\text { Arancel propuesto por el } \\
\text { profesional dependiendo del } \\
\text { caso. }\end{array}$ \\
\hline $\begin{array}{l}\text { Estrategias de marketing } \\
\text { (marketing directo, marketing } \\
\text { digital) }\end{array}$ & $\begin{array}{l}\$ 100 \text { pagadero cada mes } \\
\text { durante la duración del } \\
\text { contrato }\end{array}$ \\
\hline $\begin{array}{l}\text { Participación de eventos } \\
\text { locales e internacionales. }\end{array}$ & $\begin{array}{l}\text { Medido por porcentaje } \\
\text { dependiendo del valor del } \\
\text { contrato con proveedor: } \\
\text { Cliente } 60 \% \text { MUSIKK 40\% }\end{array}$ \\
\hline $\begin{array}{l}\text { Eventos sociales para } \\
\text { interactuar con los fans. }\end{array}$ & $0 \$$ \\
\hline
\end{tabular}

Fuente: elaboración propia.

\subsubsection{Distribución}

En cuanto a la distribución de los servicios se hará de forma directa y por medio de intermediarios, debido a que el alcance de la distribución será de tipo local en primera instancia, para luego trabajar en la distribución internacional.

La distribución se va a definir de acuerdo al lugar de origen del cliente. Inicialmente se trabajará en una promoción de mercados locales con estrategias de Marketing Digital y Marketing Directo. También, la empresa se encargará de asegurar la presencia del cliente en eventos públicos y privados con alto grado de reconocimiento. Luego se trabajará a nivel regional usando los mismos parámetros que la promoción local y por último se trabajará en mercados internacionales, se aumentará la inversión en promoción y se trabajará con intermediarios, para garantizar la adecuada penetración a los mercados en los que se quiera trabajar. Dichos mercados internacionales se elegirán estratégicamente de acuerdo al impacto que generen en sus pares Ej. Argentina o Brasil en Latinoamérica.

El hecho de que MUSIKK, se encuentre establecida legalmente en Argentina, no significa que sus oficinas físicas se encuentren dentro del país, ya que la empresa maneja como política reclutar artistas alrededor del mundo. Por lo que se estableció que en los inicios de la empresa, no se tenga una oficina física sino meramente digital por motivos económicos de los accionistas, y también el pensamiento de estar en todo el mundo. De esta manera existirá un ahorro en los costos fijos de MUSIKK. 
A pesar de no contar con una oficina física, la empresa ha reconocido la importancia de tener un lugar en el que se generen entrevistas con clientes, reuniones con proveedores, reuniones de personal, etc. Por lo que en esos casos puntuales se contratarán espacios de Co-Working ${ }^{38}$.

\subsubsection{Comunicación}

Cuando se habla de comunicación en el plan de negocios, se trata de responder a la pregunta de cómo se va a comunicar a los potenciales clientes que existe un nuevo servicio en el mercado y así deseen comprarlo ${ }^{39}$.

- Como primera estrategia de comunicación se pensó hacerlo por medio de Redes Sociales, es decir buscar y generar un contacto con el cliente potencial por medio de avisos publicitarios en Facebook, Youtube, Instragram, Twitter, entre otras. También se trabajará con portales de música en streaming con Apple Music, Spotify, SoundCloud, etc. Adicionalmente trabajará en manejo de posicionamiento en Google (SEO, SEM) y se invertirá en publicidad en sitios Web relacionados a la música.

- Presencia en festivales de música para que los clientes potenciales nos vayan conociendo.

- Comunicación más específica en Centros Educativos, Bibliotecas, Centros de recreación, etc.

\subsubsection{Recursos humanos, dirección y gerencia}

Para la creación de MUSIKK como empresa, se debe establecer una estructura organizacional, la misma que deberá cumplir con los siguientes puntos.

- Estructura de la empresa en su punto máximo de expansión. Organigrama.

\footnotetext{
${ }^{38}$ Espacios de trabajo compartidos. Varias PYMES en su mayoría, comparten oficinas y equipamientos para el desarrollo de sus empresas.

39 Terragno, L. D., \& Lecuona, M. (1999). Cómo armar un plan de negocios. Capital Federal, Argentina: Editorial Coyuntura SAC. Terragno, L. D., \& Lecuona, M. (1999). Cómo armar un plan de negocios. Capital Federal, Argentina: Editorial Coyuntura SAC.
} 


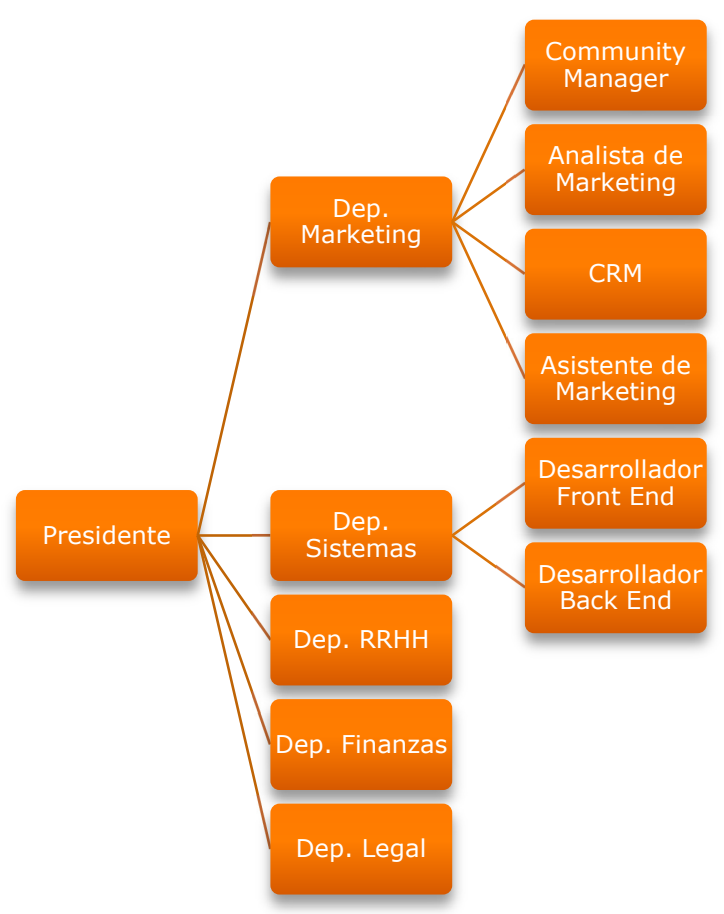

Fuente: elaboración propia

Figura 5.- Organigrama final de MUSIKK

- Estructura de la empresa al inicio y potencial crecimiento del recurso humano con el crecimiento de la empresa. Organigrama

La idea inicialmente sería subcontratar los servicios profesionales de las áreas de finanzas y de legal, para que se encarguen del manejo legal y financiero de la empresa sin pertenecer a ella y tratar de disminuir los costos en esas áreas inicialmente. 


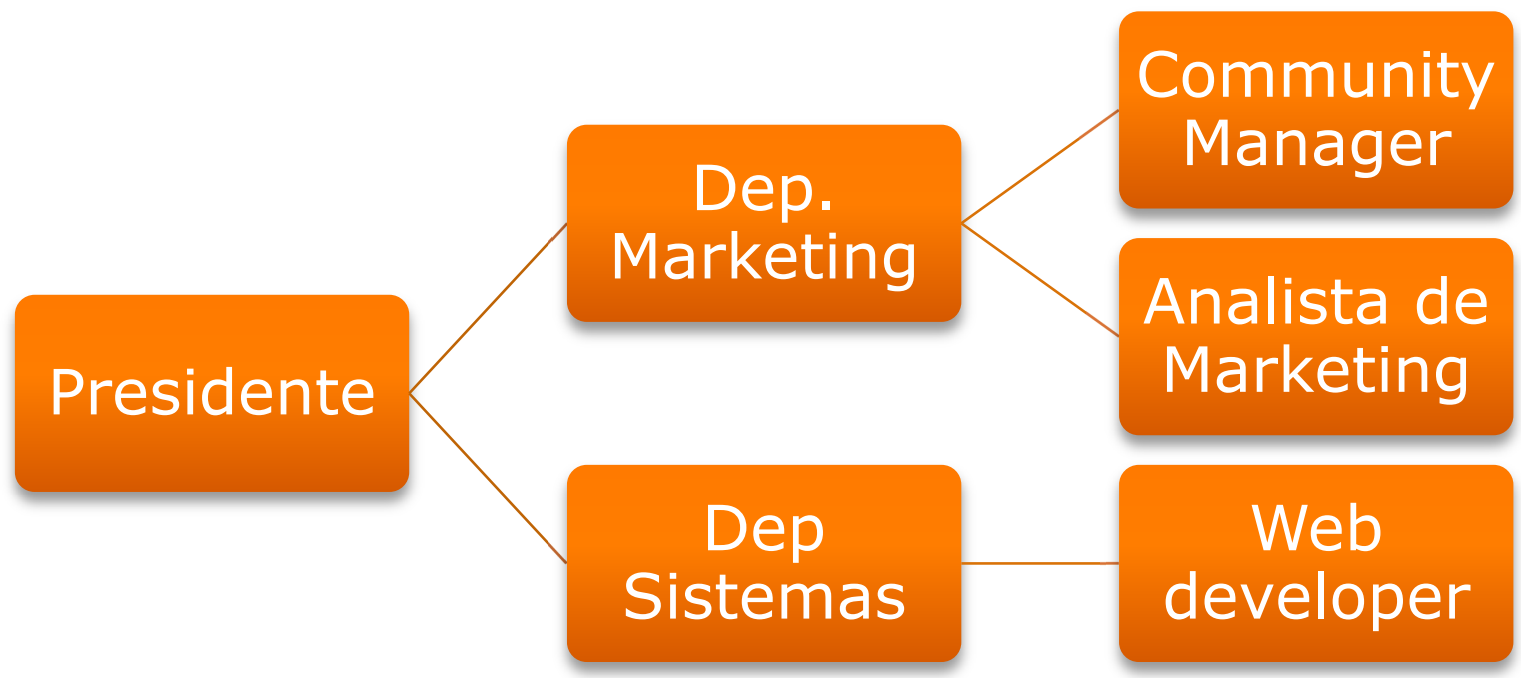

Fuente: elaboración propia

Figura 6.- Organigrama inicial MUSIKK

- Cuál será la cantidad de empleados para los siguientes dos a cinco años. 


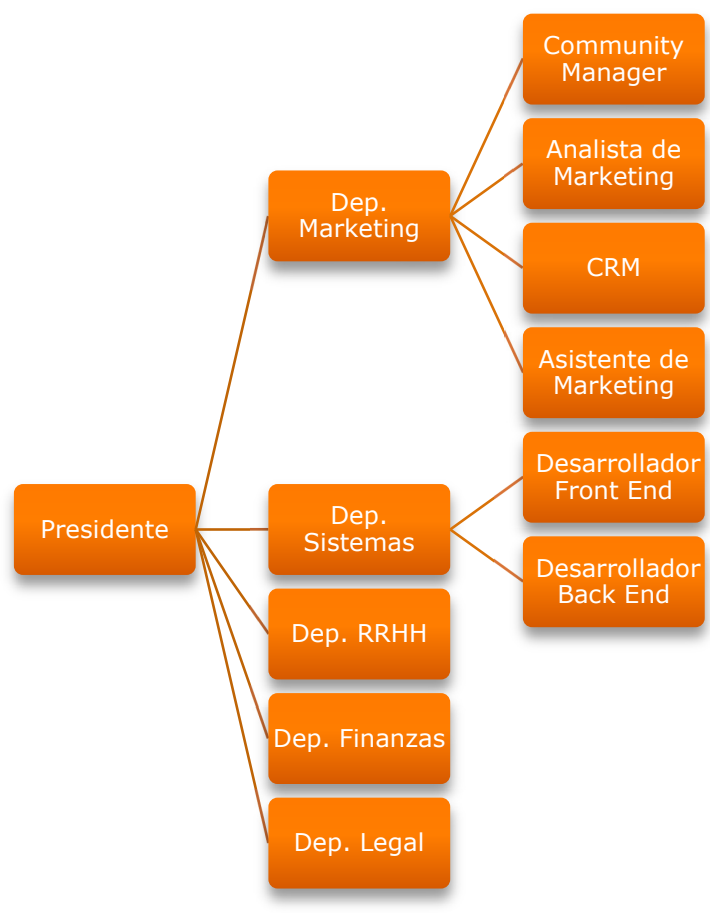

Fuente: elaboración propia

\section{Figura 7.- Organigrama explicativo}

Se pensó que la cantidad de empleados sea uno por área, pero va a depender del crecimiento real de la empresa, por lo que se pensó un número de empleados entre lo 12 20 para los 5 primeros años.

- Qué puestos ocuparán en la empresa

Cómo ya se comentó previamente, existen dos socios especialistas en los principales temas que manejará la empresa y son Sistemas y Marketing Internacional. Se pensó como presidente de la empresa al especialista en Marketing Internacional por su perfil de gestión, pero las decisiones acerca de la empresa se las tomará en conjunto entre los dos accionistas.

Cada área de la Empresa contará con un jefe de área y con los especialistas de esa área. Es así como el Departamento de Marketing tendrá al jefe de esa área, un especialista en Community Management, un analista en Marketing directo y un Especialista en Servicio al Cliente CRM (Customer Relationship Management).

El Departamento de Sistemas, tendrá también su Jefe de área acompañado por un especialista en front end development y otro en back end development. Si existiera el caso 
de necesitar más personal para el área de sistemas no se escatimarían en costos debido a que es una de las áreas más importantes de la empresa.

Siguen el Departamento de Recursos Humanos que tendrá un Jefe y único integrante en ese departamento. El Departamento de Finanzas que de igual manera tendrá un jefe y único integrante del departamento y por último el Departamento legal, que como los otros dos, el Jefe del departamento será el único integrante del área.

En todos los Departamentos descritos anteriormente, si existiera la necesidad de contratar más personal para cubrir vacantes que sean necesarias agregar, se lo hará de manera inmediata.

\subsection{Estrategia de captación}

- Para la captación de clientes se pensará primero en una estrategia de Servicio (Producto), ésta será principalmente de Estandarización ${ }^{40}$. Con esta estrategia se intenta captar clientes por la cantidad de mercados en los que trabajará MUSIKK.

- También para poder captar clientes se pensó en una estrategia de precios. Es decir, que se manejarán precios más bajos en relación a la competencia para que inicialmente los clientes elijan a MUSIKK para verse beneficiados al tener excelentes servicios a bajo costo.

- Se trata de captar clientes en los mismos medios en los que se les promocionaría al firmar el contrato con MUSIKK, ya que al estar dentro del mismo círculo tendrán más apoyo y difusión para empezar su carrera con la empresa.

\footnotetext{
${ }^{40}$ Bradley, F. Marketing Internacional 5ta Edición. Editorial Pearson - Prentice Hall.
} 


\section{Capítulo IV. Análisis de factibilidad del plan de negocios.}

4. Análisis de factibilidad del plan de negocios.

\subsection{Recursos e inversiones}

Este sección del análisis de factibilidad, demostrará los recursos necesarios para que MUSIKK pueda empezar con sus actividades empresariales, dónde y cómo se obtendrán según las necesidades de inversión ${ }^{41}$.

Tabla 3 Recursos e Inversiones de MUSIKK

\begin{tabular}{|l|r|l|}
\hline Recursos & Inversión en USD & Observaciones \\
\hline $\begin{array}{l}\text { Selección y contratación de } \\
\text { personal }\end{array}$ & $\$ 0$ & $\begin{array}{l}\text { Inicialmente, no se pensó } \\
\text { invertir en selección y } \\
\text { contratación de personal, } \\
\text { debido a que los accionistas } \\
\text { son los mismos profesionales } \\
\text { que se encargarán de poner en } \\
\text { marcha el negocio. }\end{array}$ \\
\hline Equipos Tecnológicos & $\$ 5.000$ & PCs 2 \\
\hline $\begin{array}{l}\text { Inscripciones, registros y } \\
\text { licencias }\end{array}$ & $\$ 2.500$ & Sitio Web, Servidor, Dominio \\
\hline $\begin{array}{l}\text { Capacitación y } \\
\text { Entrenamiento }\end{array}$ & $\$ 2.000$ & Uso de nuevas tecnologías. \\
\hline Investigación de Mercado & $\$ 1.000$ & \\
\hline
\end{tabular}

${ }^{41}$ Terragno, L. D., \& Lecuona, M. (1999). Cómo armar un plan de negocios. Capital Federal, Argentina: Editorial Coyuntura SAC. Terragno, L. D., \& Lecuona, M. (1999). Cómo armar un plan de negocios. Capital Federal, Argentina: Editorial Coyuntura SAC. 


\begin{tabular}{|l|r|l|}
\hline Publicidad y Promoción & $\$ 3.000$ & Redes Sociales y Eventos \\
\hline Capital de trabajo & $\$ 3.000$ & $\begin{array}{l}\text { Capital que usará la empresa } \\
\text { hasta tener sus primeros } \\
\text { ingresos. }\end{array}$ \\
\hline
\end{tabular}

Fuente: elaboración propia.

La cantidad de dinero para la inversión inicial para MUSIKK es de USD 16.500 para poner en funcionamiento la empresa. Esta inversión saldrá de los accionistas y creadores de la empresa, por eso los mismos en un inicio se encargarán del manejo de los dos departamentos principales de MUSSIK, el Departamento de Marketing y el Departamento de Sistemas.

De esta forma se tratará de que haya mayores ingresos a comparación de los gastos, para de esa forma, seguir invirtiendo en el crecimiento de la empresa.

\subsection{Factibilidad técnica}

En la sección de la factibilidad técnica, se responderán a indicadores en los cuáles se demuestre que es posible poner en práctica la idea de negocio y sostenerla en el tiempo.

Al responder a los indicadores que se enumerarán a continuación se tratará de demostrar la factibilidad de la idea de negocio.

- Ensayo o investigación: Los servicios de MUSIKK ya fueron aplicados a un músico profesional en crecimiento, él es de Nápoles Italia y su nombre artístico es IOSSA. Él es cantautor de música Pop/Rock y está buscando expandirse en otros mercados internacionales, por lo que aceptó ser usuario de los servicios de la Agencia de Representación.

- Ubicación: Cómo ya lo habíamos explicado anteriormente, MUSSIK está inscripta legalmente en Argentina, pero no tiene un lugar físico de ubicación, debido que los profesionales estarán en distintas partes del mundo haciendo el trabajo de captar clientes, por lo que se caracterizará en hacer trabajos remotos desde la modalidad home office. En el caso de necesitar un lugar físico para cualquier tipo de reunión se contratarán espacios de Co-Working en el lugar que necesite.

- Tecnología: Todo el manejo tecnológico del área de sistemas lo realizará el especialista del área que también es accionista de la empresa. Mientras que el 
manejo de redes sociales lo hará la especialista de marketing. Toda esta tecnología ya fue probada y se la mostrará más adelante con el caso aplicativo.

- Personal: Los especialistas de la empresa recibirán capacitación continuamente para brindar un excelente servicio al cliente y a su vez puedan aplicar en los clientes las últimas tendencias del medio.

\subsection{Factibilidad económica}

Con la factibilidad económica, se debe demostrar que el proyecto sobrevivirá económicamente, es decir que la inversión realizada es suficiente para que el negocio genere ganancia ${ }^{42}$.

\subsubsection{Ventas}

Se estimó que para recuperar la inversión realizada en el proyecto y para obtener utilidad se deben tener al menos 30 ventas anuales, si calculamos que cada paquete promocional se encuentra en un promedio de USD 3.000, se llagarán a USD 90.000 de ganancias en el primer año de inversión.

\subsubsection{Costos}

En cuanto a los costos del proyecto, se determinaron los costos fijos y los costos variables. Los cuáles estarán descritos a continuación.

Tabla 4 Año 1 Costos fijos y variables

\begin{tabular}{|l|r|l|}
\hline Año 1 & $\begin{array}{l}\text { Costos fijos } \\
\text { (USD) }\end{array}$ & $\begin{array}{l}\text { Costos variables } \\
\text { (USD) }\end{array}$ \\
\hline $\begin{array}{l}\text { Selección y contratación de } \\
\text { personal }\end{array}$ & $\$ 0$ & $\$ 0$ \\
\hline Equipos Tecnológicos & $\$ 500$ & \\
\hline Inscripciones, registros y & & \\
\hline licencias & & \\
\hline Capacitación y & & \\
\hline
\end{tabular}

${ }^{42}$ Terragno, L. D., \& Lecuona, M. (1999). Cómo armar un plan de negocios. Capital Federal, Argentina: Editorial Coyuntura SAC. 


\begin{tabular}{|l|r|r|}
\hline Entrenamiento & & \\
\hline Investigación de Mercado & $\$ 1.000$ & \\
\hline Publicidad y Promoción & $\$ 3.000$ & \\
\hline Capital de trabajo & & \\
\hline
\end{tabular}

Fuente: Elaboración propia.

Tabla 5 Año 2 Costos fijos y variables

\begin{tabular}{|l|r|l|}
\hline Año 2 & $\begin{array}{l}\text { Costos fijos } \\
\text { (USD) }\end{array}$ & $\begin{array}{l}\text { Costos variables } \\
\text { (USD) }\end{array}$ \\
\hline $\begin{array}{l}\text { Selección y contratación de } \\
\text { personal }\end{array}$ & $\$ 0$ & \\
\hline $\begin{array}{l}\text { Equipos Tecnológicos } \\
\text { licencias }\end{array}$ & $\$ 500$ & \\
\hline $\begin{array}{l}\text { Capacitación y } \\
\text { Entrenamiento }\end{array}$ & $\$ 1.000$ \\
\hline Investigación de Mercado & $\$ 1.000$ & \\
\hline Publicidad y Promoción & $\$ 3.000$ & \\
\hline Capital de trabajo & & \\
\hline
\end{tabular}

Fuente: elaboración propia.

Tabla 6 Año 3 Costos fijos y Variables

\begin{tabular}{|l|l|l|}
\hline Año 3 & $\begin{array}{l}\text { Costos fijos } \\
\text { (USD) }\end{array}$ & $\begin{array}{l}\text { Costos variables } \\
\text { (USD) }\end{array}$ \\
\hline $\begin{array}{l}\text { Selección y contratación de } \\
\text { personal }\end{array}$ & $\$ 0$ & \\
\hline
\end{tabular}




\begin{tabular}{|l|r|r|}
\hline Equipos Tecnológicos & & \\
\hline $\begin{array}{l}\text { Inscripciones, registros y } \\
\text { licencias }\end{array}$ & $\$ 500$ & \\
\hline $\begin{array}{l}\text { Capacitación y } \\
\text { Entrenamiento }\end{array}$ & $\$ 2.000$ & \\
\hline Investigación de Mercado & $\$ 1.000$ & \\
\hline Publicidad y Promoción & $\$ 3.000$ & \\
\hline Capital de trabajo & & \\
\hline
\end{tabular}

Fuente: Elaboración propia.

Tabla 7 Año 4 Costos fijos y variables

\begin{tabular}{|l|r|l|}
\hline Año 4 & $\begin{array}{l}\text { Costos fijos } \\
\text { (USD) }\end{array}$ & $\begin{array}{l}\text { Costos variables } \\
\text { (USD) }\end{array}$ \\
\hline $\begin{array}{l}\text { Selección y contratación de } \\
\text { personal }\end{array}$ & $\$ 0$ & \\
\hline Equipos Tecnológicos & $\$ 500$ & \\
\hline $\begin{array}{l}\text { Inscripciones, registros y } \\
\text { licencias }\end{array}$ & $\$ 1.000$ \\
\hline $\begin{array}{l}\text { Capacitación y } \\
\text { Entrenamiento }\end{array}$ & $\$ 2.000$ & \\
\hline Investigación de Mercado & $\$ 1.000$ & \\
\hline Publicidad y Promoción & $\$ 3.000$ & \\
\hline Capital de trabajo & & \\
\hline
\end{tabular}

Fuente: Elaboración propia. 
Tabla 8 Año 5 Costos fijos y variables

\begin{tabular}{|l|r|l|}
\hline Año 5 & $\begin{array}{l}\text { Costos fijos } \\
\text { (USD) }\end{array}$ & $\begin{array}{l}\text { Costos variables } \\
\text { (USD) }\end{array}$ \\
\hline $\begin{array}{l}\text { Selección y contratación de } \\
\text { personal }\end{array}$ & $\$ 0$ & \\
\hline Equipos Tecnológicos & $\$ 500$ & \\
\hline $\begin{array}{l}\text { Inscripciones, registros y } \\
\text { licencias }\end{array}$ & & \\
\hline $\begin{array}{l}\text { Capacitación y } \\
\text { Entrenamiento }\end{array}$ & $\$ 2.000$ & \\
\hline Investigación de Mercado & $\$ 1.000$ & \\
\hline Publicidad y Promoción & $\$ 3.000$ & \\
\hline Capital de trabajo & & \\
\hline
\end{tabular}

Fuente: Elaboración propia.

\subsection{Factibilidad financiera}

Para medir si el proyecto es factible o no, se debe sacar el Valor Actual Neto (VAN) y la Tasa Interna de Retorno (TIR).

Tabla 9 VAN y TIR

\begin{tabular}{|l|l|l|l|l|l|}
\hline Inversión Inicial USD & Año 1 USD & Año 2 USD & Año 3 USD & Año 4 USD & Año 5 USD \\
\hline
\end{tabular}

$\$ 16.500$

\begin{tabular}{|l|r|r|r|r|r|}
\hline Ingresos anuales 15\% & $\$ 90.000$ & $\$ 103.500$ & $\$ 119.025$ & $\$ 136.878$ & $\$ 157.410$ \\
\hline Costos Fijos & $\$ 6.500$ & $\$ 6.500$ & $\$ 6.500$ & $\$ 6.500$ & $\$ 6.500$ \\
\hline Costos Variables & $\$ 3.000$ & $\$ 5.000$ & $\$ 5.000$ & $\$ 7.000$ & $\$ 7.000$ \\
\hline Rentabilidad/TIR & $\$ 73.181$ & $\$ 76.033$ & $\$ 80.785$ & $\$ 84.269$ & $\$ 89.357$ \\
\hline
\end{tabular}




\begin{tabular}{|l|r|}
\hline VAN & $\$ 403.626$ \\
\hline
\end{tabular}

Fuente: Elaboración propia.

El análisis de factibilidad financiera, demostró una VAN positiva lo que nos quiere decir que el proyecto es factible y que la inversión realizada se recuperará en el primer año si las ventas se mantienen según lo planificado.

En el análisis se puede observar que a partir del primer año ya se obtiene una rentabilidad que supera ampliamente la inversión inicial, por lo que queda la opción de devolver la inversión inicial a los accionistas más un $10 \%$ de interés, quedando de esta forma USD \$55.581 para invertir en la compañía y así asegurar su crecimiento, siempre y cuando se trate de mantener el $15 \%$ de rendimiento anual.

Con esa rentabilidad se decidió que un porcentaje el $50 \%$, quede destinado para la inversión en estrategias de Marketing tanto para MUSIKK como para sus clientes, para aumentar las ventas por medio de la publicidad en la que se invertirá por varios medios de difusión.

También dentro del otro $50 \%$ se contemplará como reserva en el caso que los costos variables, aumenten con relación a lo planificado, de esta forma no se estaría solventando esas fluctuaciones con el porcentaje dedicado al marketing de la empresa, por lo que la visión de crecimiento estaría intacta a pesar de dichos cambios. 


\section{Capítulo V. Caso Aplicativo.}

\section{Caso aplicativo}

Se ha tomado como caso aplicativo a un músico del género Rock/pop que se encuentra en potencial crecimiento y su nombre artístico es IOSSA. A continuación se hará una descripción de IOSSA ${ }^{43}$.

\subsection{Descripción}

Angelo lossa, nacido el 3 de marzo del 1987 en Caserta, Italia. Cantante, escritor nacido para entretener. Influenciado por muchos estilos y géneros musicales, aun prefiere principalmente sonidos Pop.

Su carrera empezó con el programa de televisión de talento "AMICI DI MARIA de FILIPPI" en 2009, luego en el musical "C'ERA UNA VOLTA...SCUGNIZZI" en 2010.

Luego del musical, él empezó a proyectar su vida y a escribir sus canciones y a interpretarlas en música electrónica, colaborando con DJ's, productores como John Dahlback, ChadashCort, Mindshake, y Daddy'sGroove.

La colaboración entre IOSSA, Mindshake y Daddy'sGroove dio como resultado el proyecto "Surrender", coproducido y aprobado por David Guetta. Al llegar al top 5 de beat, Surrender promocionado en el medio por Jack Back Records/Ultra Music Record.

IOSSA también se destacó en el video, grabado en Ibiza. Sus tracks más populares y destacados en música Dance son "Smile by Feng Shui", "My rise my fall" ambas escritas por Mindshake y promocionadas por Rise/Time Records.

En 2015 IOSSA decidió íntimamente trabajar más tiempo en su nueva discografía, dando como resultado al Álbum Indie "UnpluggedLive", una sesión acústica en vivo con el joven guitarrista Emilio Lanza. El álbum es seguido por la hermosa romántica balada "Here I am".

\footnotetext{
${ }^{43}$ IOSSA. (2015). Iossa oficial. Retrieved 25 de 01 de 2017 from Iossa oficial: http://www.iossaofficial.com/
} 
IOSSA ha tenido algunas presentaciones en espectáculos como Livepa, combinando su presentación en vivo con Sets de Dj's como "Plugged with Anfisa Letyago”, "Unplugged live show", una presentación única en un solo guitarra acústica.

\subsection{Estilo de IOSSA}

IOSSA tiene un estilo musical suave del género pop, con tendencias al romanticismo, en su mayoría él interpreta sus canciones en inglés, demostrando también los cambios en su voz al momento de interpretarlas. Adicionalmente su estilo musical va muy acorde a su personalidad, lo cual hace que exista una armonía en cada interpretación.

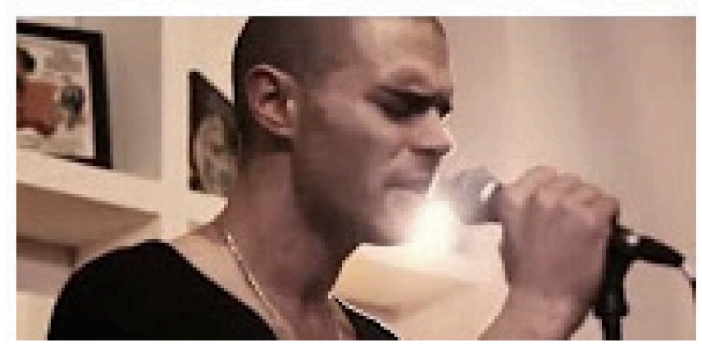

Figura 8.- IOSSA

En cuanto a su estilo personal, es una persona extrovertida al momento de interpretar su música, humilde y muy agradable. Su vestimenta y accesorios son informales muy acorde al mercado al que se apunta que son personas interesadas en el género pop en inglés de sexo indistinto con un rango etario de 14 a 45 por país en el que se quiera promocionar la carrera de IOSSA. 


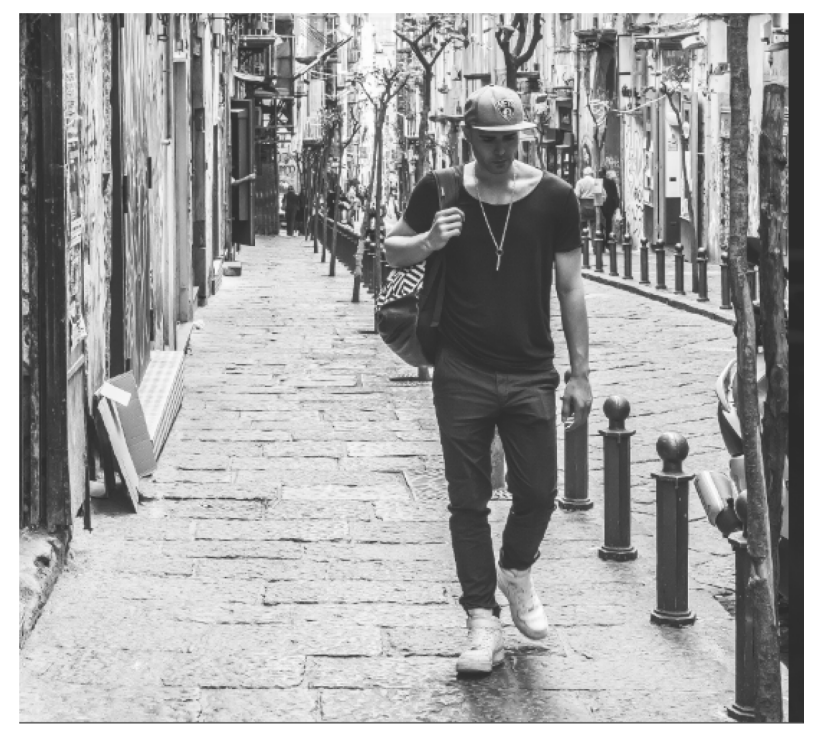

\section{Figura 9.- Estilo IOSSA}

Una vez que se identificó el mercado meta, se pudo trabajar en las estrategias que ya fueron implementadas por la Agencia de representación y que se describirán más adelante.

También se pensaron en estrategias que se pueden implementar en un futuro para ganar mayor proporción del mercado meta establecido, o llegar a nuevos mercados (Mercado país). El estilo musical y personal de IOSSA se tomó como guía para promocionar su imagen de marca. 
5.3. Mapa de posicionamiento

\section{Costos (+)}
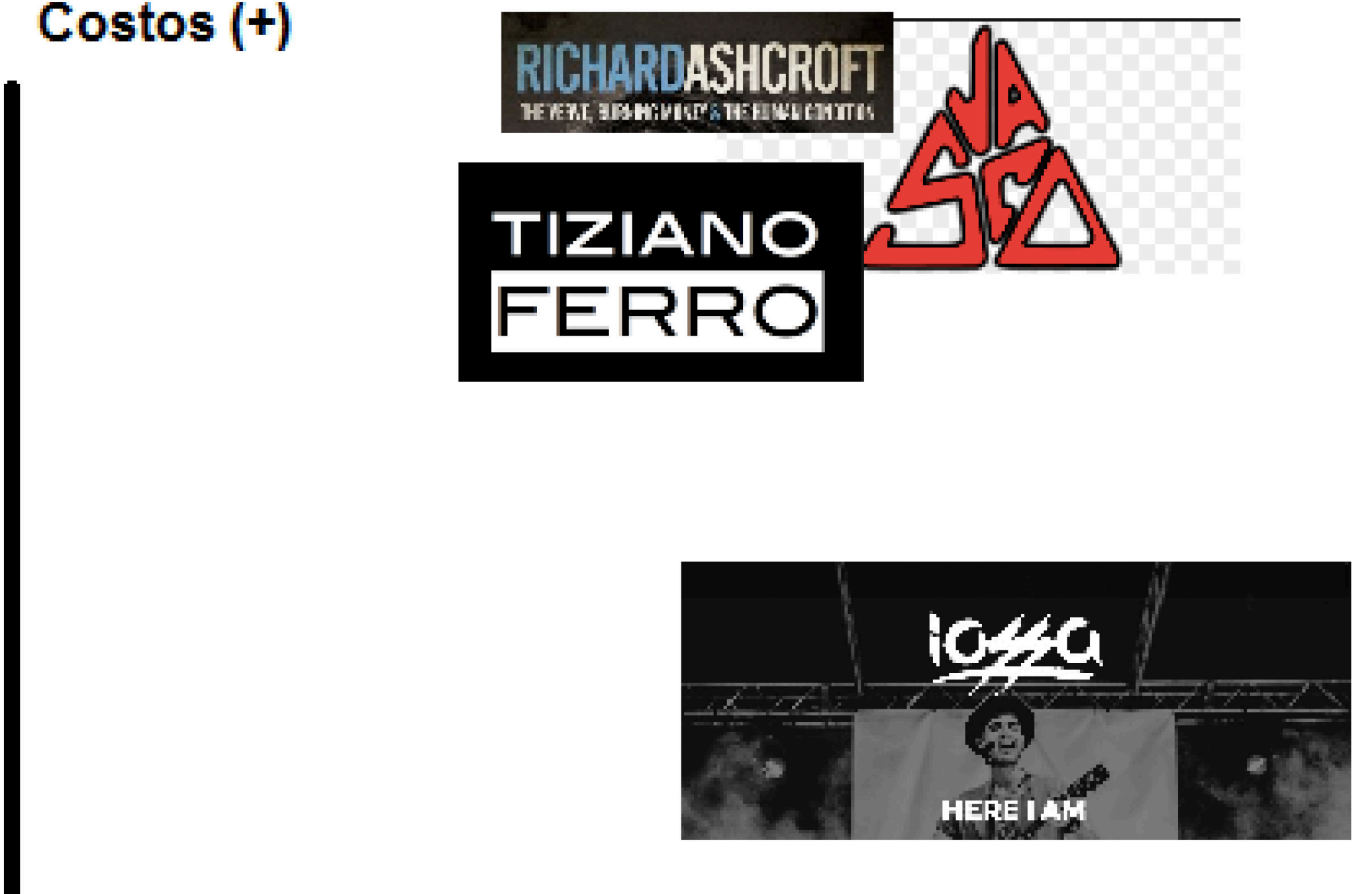

Idoneidad (-)

Tdoineidad (+)

\section{Costos (-)}

Fuente: elaboración propia

Figura 10.- Mapa de posicionamiento costo - idoneidad IOSSA

En este mapa de posicionamiento, podemos observar que IOSSA a comparación con otros artistas como son Vasco Rossi, Tiziano Ferro y Richard Ashcroft, maneja costos menores a pesar de ser muy idóneo y talentoso en sus obras musicales. Estos costos están directamente relacionados con el nivel de fama de estos artistas, entre más fama mayores serán sus costos pero también sus ganancias. Por lo que al mirar el posicionamiento que tiene actualmente IOSSA, se debe seguir invirtiendo en las estrategias para poder alcanzar el nivel de fama de sus competidores. 


\section{Estilos musicales}

$(+)$
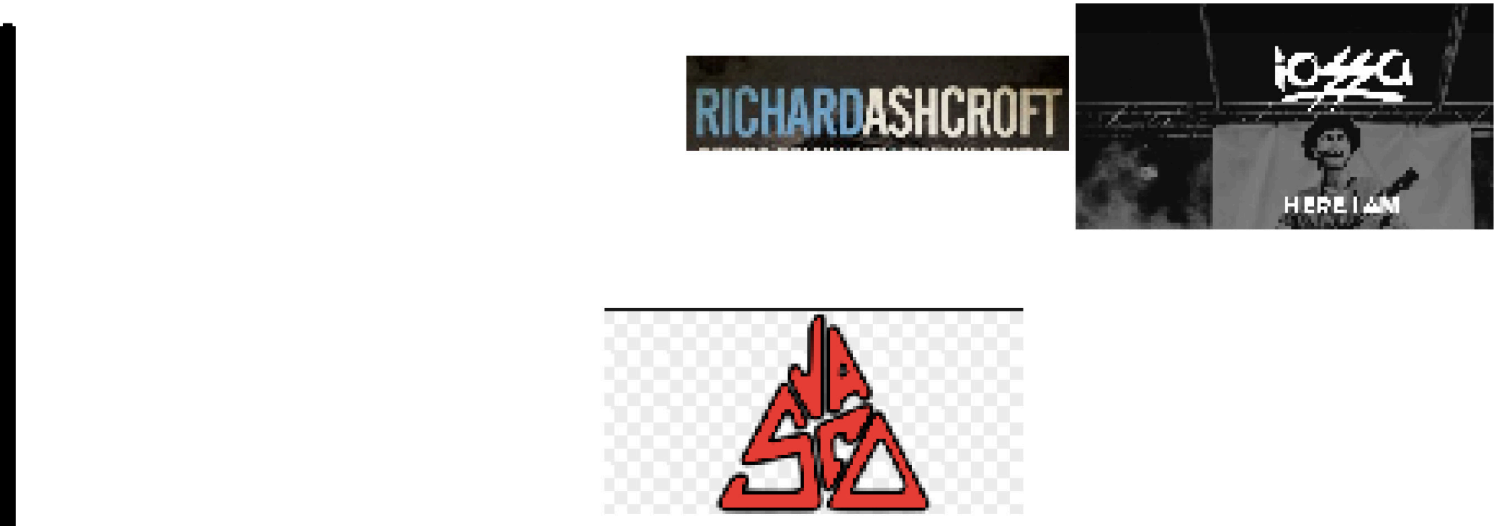

\section{TIZIANO} FERRO

\section{Un mercado}

\section{Varios mercados}

\section{Estilos musicales}

(-)

Fuente: elaboración propia

Figura 11.- Mapa de posicionamiento estilos musicales - mercado IOSSA

En cuanto al posicionamiento de IOSSA con respecto a los estilos musicales, se puede observar que tiene la capacidad de manejar una variedad de estilos musicales de acuerdo al mercado en el que se esté enfocando, lo cual se debe aprovechar para el enfoque de cada estrategia dedicada a cada mercado. Esta característica se la debe aprovechar como una ventaja competitiva frente a la competencia con la que tiene que lidiar IOSSA en cada momento. 


\section{Radio (+)}

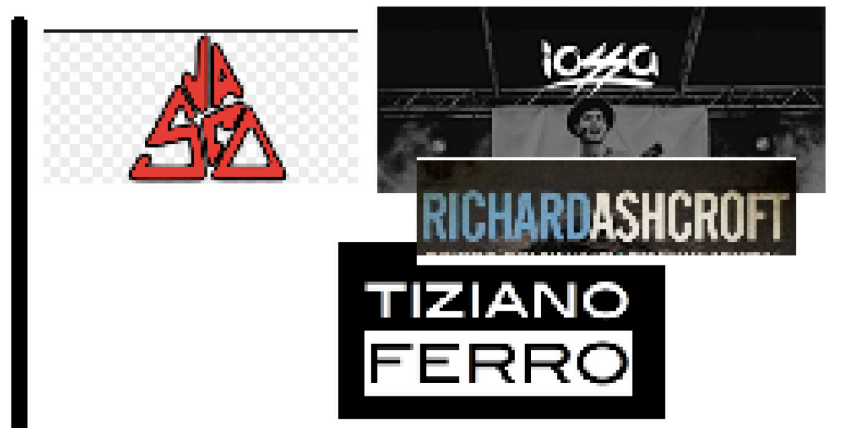

\section{Dance (-) \\ Dance (+)}

\section{Radio (-)}

Fuente: elaboración propia

\section{Figura 12.- Mapa de posicionamiento radio - dance IOSSA}

En este mapa de posicionamiento se puede observar que IOSSA, es más radial en su música, es decir, que su música sería de gran éxito en las radios debido a su estilo musical en cuanto al pop/rock romántico. Pero a su vez también tiene música más de tipo Dance. Esta versatilidad que él tiene es de gran importancia para promocionarlas con Estrategias de Marketing, ya que no solamente se estará enfocando en un mercado sino en varios.

\subsection{Estrategias de Marketing del Cantautor}

\subsubsection{Existentes}

\subsubsection{Diversificación}

Como ya se mencionó con anterioridad, IOSSA tiene una gran capacidad de adaptación para interpretar distintos estilos musicales. Tanto así que se le recomendó que adicional a su música pop, también interprete temas más movidos cómo de música electrónica, lo cual lo 
pudo lograr acompañando a artistas de música electrónica en temas muy interesantes de este género, de esta manera se trata de mantener esa versatilidad para que siga trabajando de esta forma. Esto se pensó tomando el ejemplo del Cantante Richard Ashcroft (ex vocalista de la banda The Verve), que interpreta su música como solista y es de un estilo de rock, pop/rock, baladas rock y que también incursionó en el medio nocturno con sus sonidos electrónicos, pero sin dejar de lado su base rock, lo que le da la opción de participar y ser conocido tanto en el mundo del rock como en el de la vida nocturna con los temas de música electrónica.

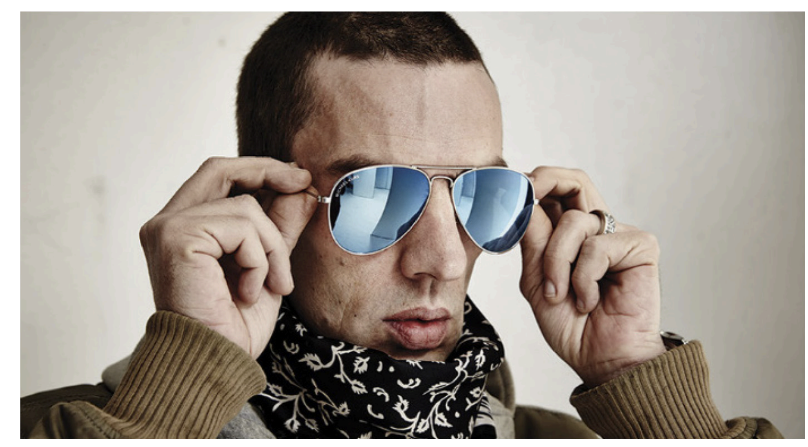

Figura 13.- Richard Ashcroft

Una estrategia muy importante de marketing fue la creación del sitio Web en el que se muestra a la marca IOSSA, que se la estableció al ser el apellido y nombre artístico del cantante, por lo que a continuación se definió el logotipo, el mismo que se promocionará en el sitio Web creado para el artista. Las características del logotipo son letras con toques pincelados que va a depender del color de fondo para destacarse y el color de la tipografía que puede ser de color negro o blanco. En el caso de la Web el fondo es oscuro por lo que las letras son blancas. En la Web se mantiene el formato oscuro pero también con una imagen en blanco y negro de IOSSA en una de sus interpretaciones en vivo, dicha imagen está plasmada en la Web por más que se cambien de secciones dentro de la misma. 


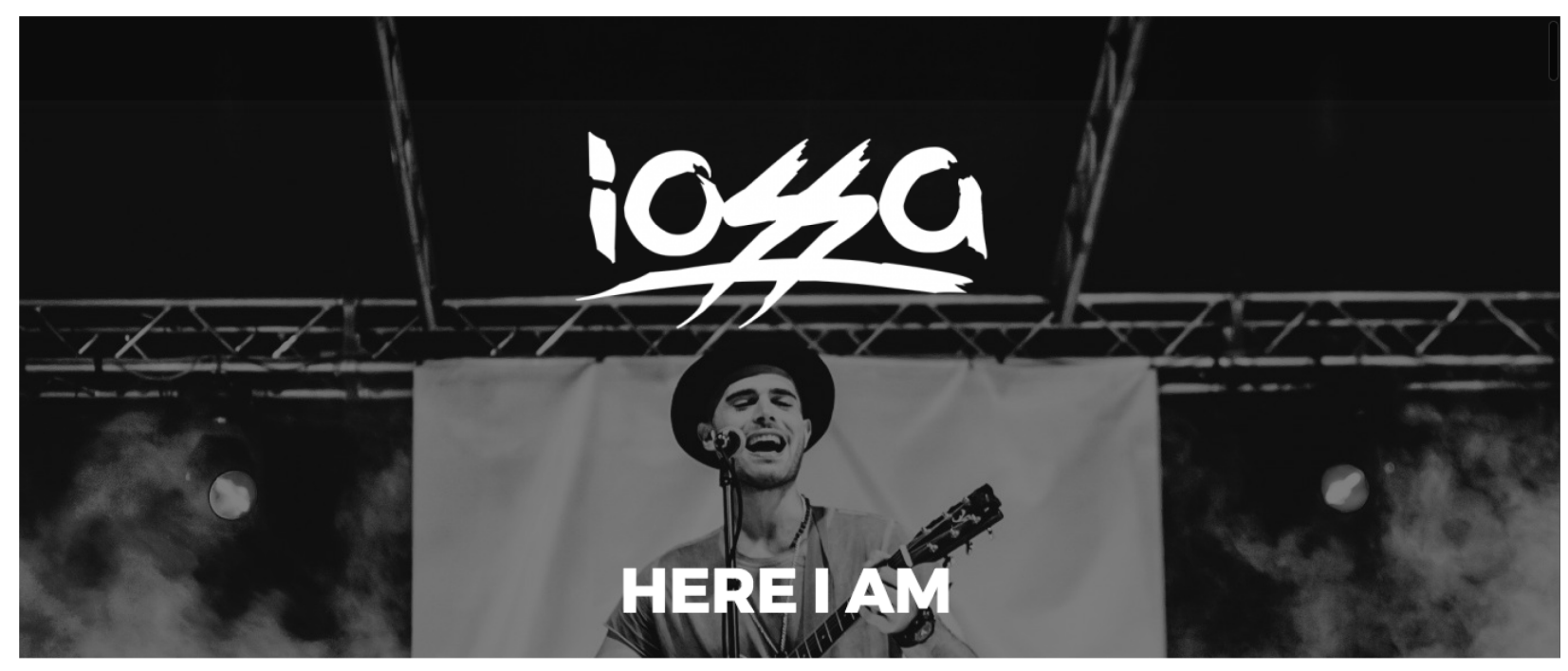

Figura 14.- Web IOSSA

También, se puede observar a la frase "Here I am", dicha frase quedó como el slogan del cantante, en el que se trata de demostrar su autoría pura en todos sus temas aparte de que "Here I am" tiene como nombre a una de las canciones más importantes para IOSSA ${ }^{44}$ Adicionalmente, en la Web se puede encontrar toda la información de los discos grabados por el cantante con una lista de canciones y videos. Entonces se colocó toda esta información en la Web debido a que se pensó promocionarla por distintos medios y redes sociales para que los usuarios o el público pueda tener mayor acceso a las canciones y videos para que lo puedan compartir con su círculo en redes sociales y también compartir todo lo que hace IOSSA en las redes al utilizar el siguiente hashtag.

\section{Figura 15.- Hashtag IOSSA}

Es por esta razón que se ideó distintas estrategias de marketing en las que está directamente relacionada la Web de IOSSA, ya que al encontrarse fotos, videos y también información del artista, cómo sus próximas presentaciones, su presencia en redes sociales y portales de música streaming, brinda de una forma compilada todo lo que se quiere dar a conocer de IOSSA principalmente su discografía, que es lo que esencialmente se quiso

${ }^{44}$ IOSSA. (2015). Iossa oficial. Retrieved 25 de 01 de 2017 from Iossa oficial: http:/www.iossaofficial.com/ 
promover y que se logró al estar sus canciones en algunas redes y disponibles para ser descargadas en itunes por 0,99 Euros cada una.

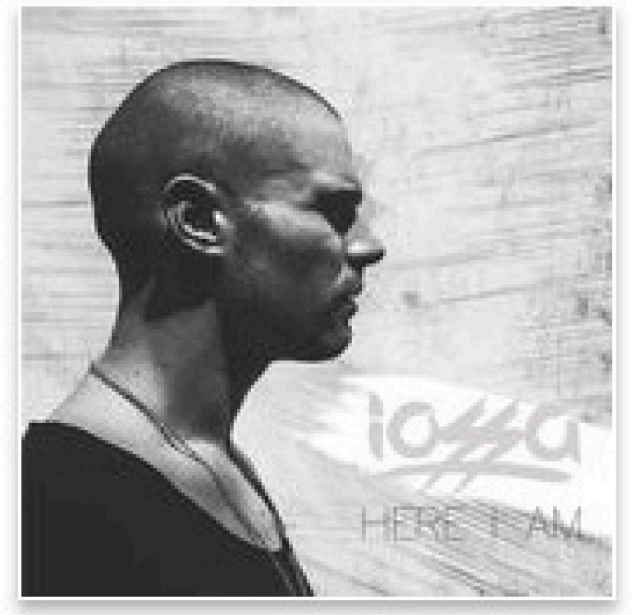

Figura 16.- Disco "Here I am"
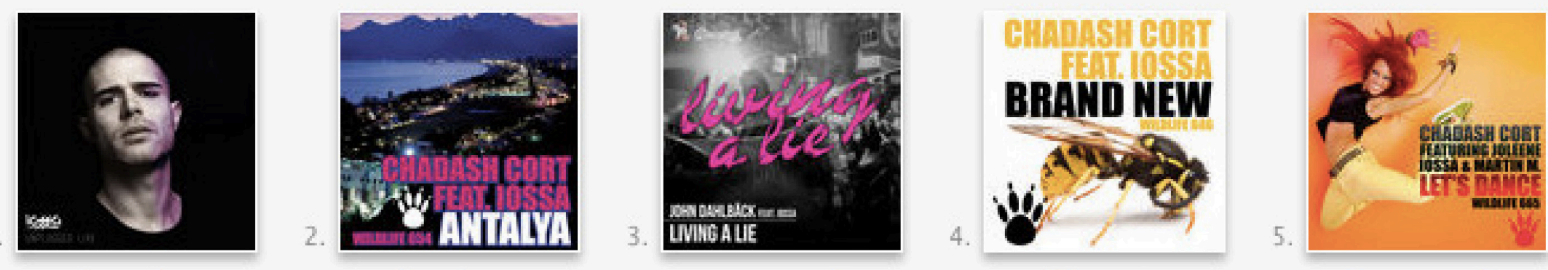

Figura 17.- Discografía IOSSA

Además de todo el contenido del sitio Web, se adicionó un press kit en el que se puede encontrar el logo de IOSSA en distintos formatos digitales, y modelos de flyers. Los mismos que son muy útiles para usarlos en la publicidad de IOSSA a través de distintos medios de promoción. 


\section{0 ga}

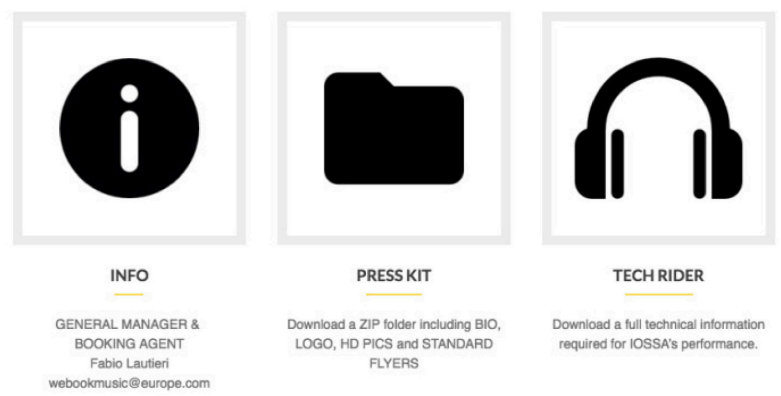

Figura 18.- Presskit IOSSA

Existe también un espacio en el que constan detalladamente las indicaciones técnicas que debe existir para que IOSSA pueda interpretar sus canciones y finalmente un botón de "info" para contactarse directamente con la representación local.

Otra estrategia que se pensó, e implementó es la presencia en Redes Sociales y en portales de música streaming, las cuáles se mostrarán a continuación.

\section{ionge}

\section{CONTACT IOSSA}

"CAUSE IT'S ALL ABOUT THE PLEASES AND THE THANK YOUS, ALL THE WRONGS AND ALL THE RIGHTS" (WHY CAN'T I)

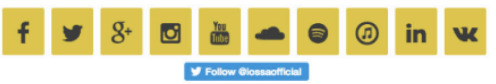

Figura 19.- Redes Sociales IOSSA

\subsubsection{Redes sociales}

\section{facebook}

Facebook, cuenta con más de 1.350 millones de miembros alrededor del mundo y está traducido en 70 idiomas. Para IOSSA @iossaoficial, se creó su presencia en esta red social con el fin de alcanzar a más usuarios y convertirlos en fans por medio de fotos, videos, estados, en los cuáles puede interactuar con los mismos. Su página está siendo actualizada una vez por día para de esta forma aumentar su audiencia cada día. Al momento IOSSA 
cuenta con 21.331 likes, lo que significa que se tiene un número importante de seguidores, que son en gran mayoría quienes ya compraron a IOSSA como cantante y como marca ${ }^{45}$.

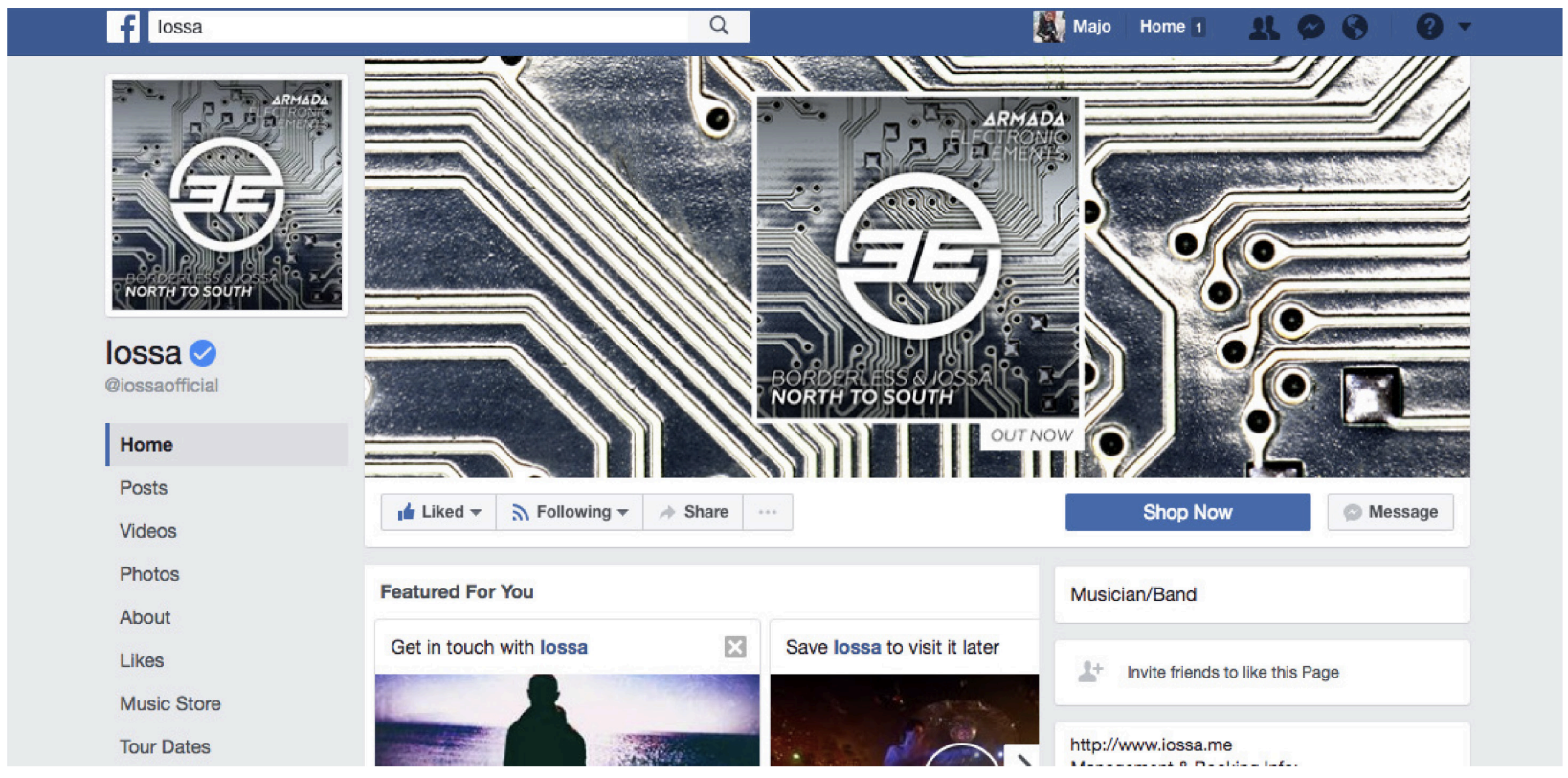

Figura 20.- Facebook IOSSA

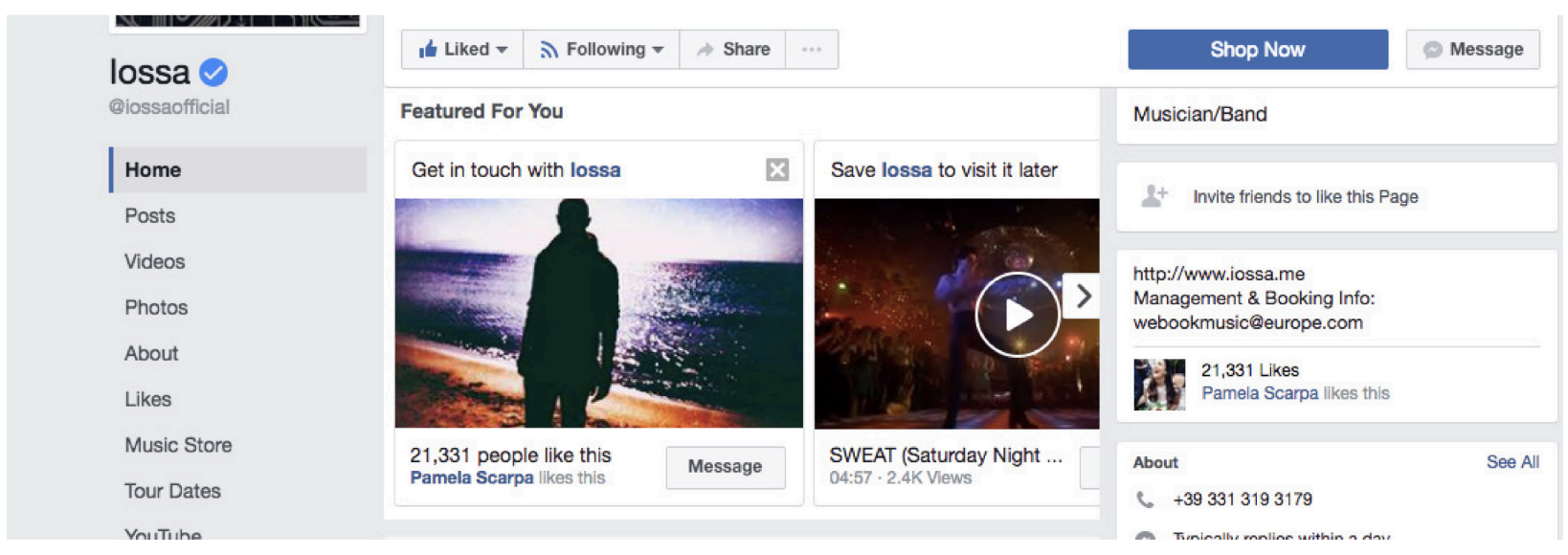

Figura 21.- Facebook "likes" IOSSA

\section{Ewikter}

${ }^{45}$ Facebook. (2017). Facebook.com. Retrieved 20 de 02 de 2017 from lossa oficial: https://www.facebook.com/iossaofficial 
Con 332 millones activos es una red social, en la cual se puede escribir mensajes o tweets públicos de texto plano de corta longitud al permitir 144 caracteres. Se creó la presencia de IOSSA al crear una cuenta, para dar noticias o anuncios importantes principalmente. La cuenta @iossaoficial ahora tiene 820 seguidores y va en aumento ${ }^{46}$.

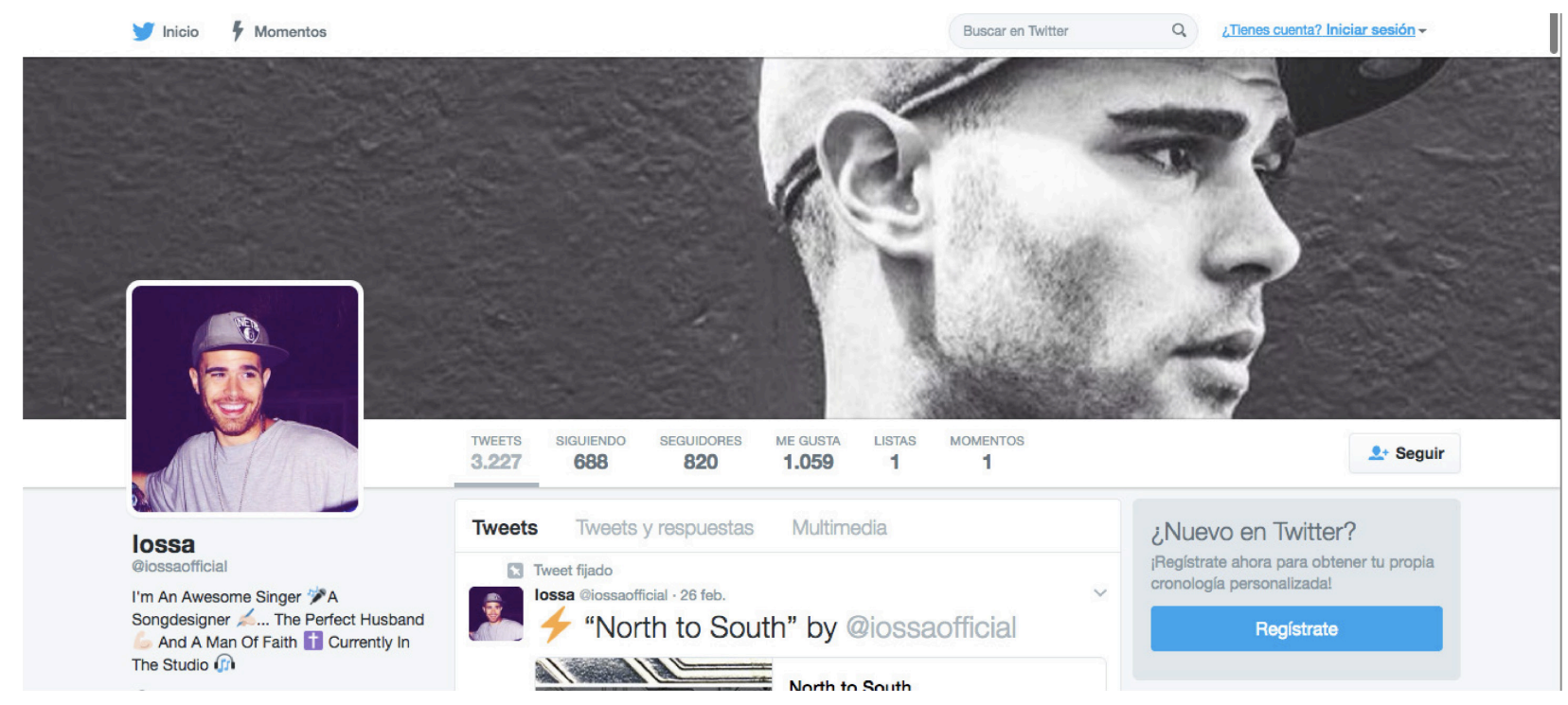

Figura 22.- Twitter IOSSA

\section{Google+}

Con más de 1000 millones de usuarios, Google+ es la segunda red social más usada en el mundo, no por ser popular sino por estar anexada a YOUTUBE. De igual manera se generó una cuenta en esta red social para IOSSA, la misma que no es tan popular ya que cuenta solamente con 24 seguidores. Lo que nos da un indicio para aumentar los seguidores para esta red social ${ }^{47}$.

\footnotetext{
${ }^{46}$ Twitter. (2017). Twitter.com. Retrieved 20 de 02 de 2017 from lossa oficial: https://twitter.com/iossaofficial

${ }^{47}$ Google+. (2017). Google+.com. Retrieved 20 de 02 de 2017 from +lossa oficial: https://plus.google.com/+iossaofficial
} 


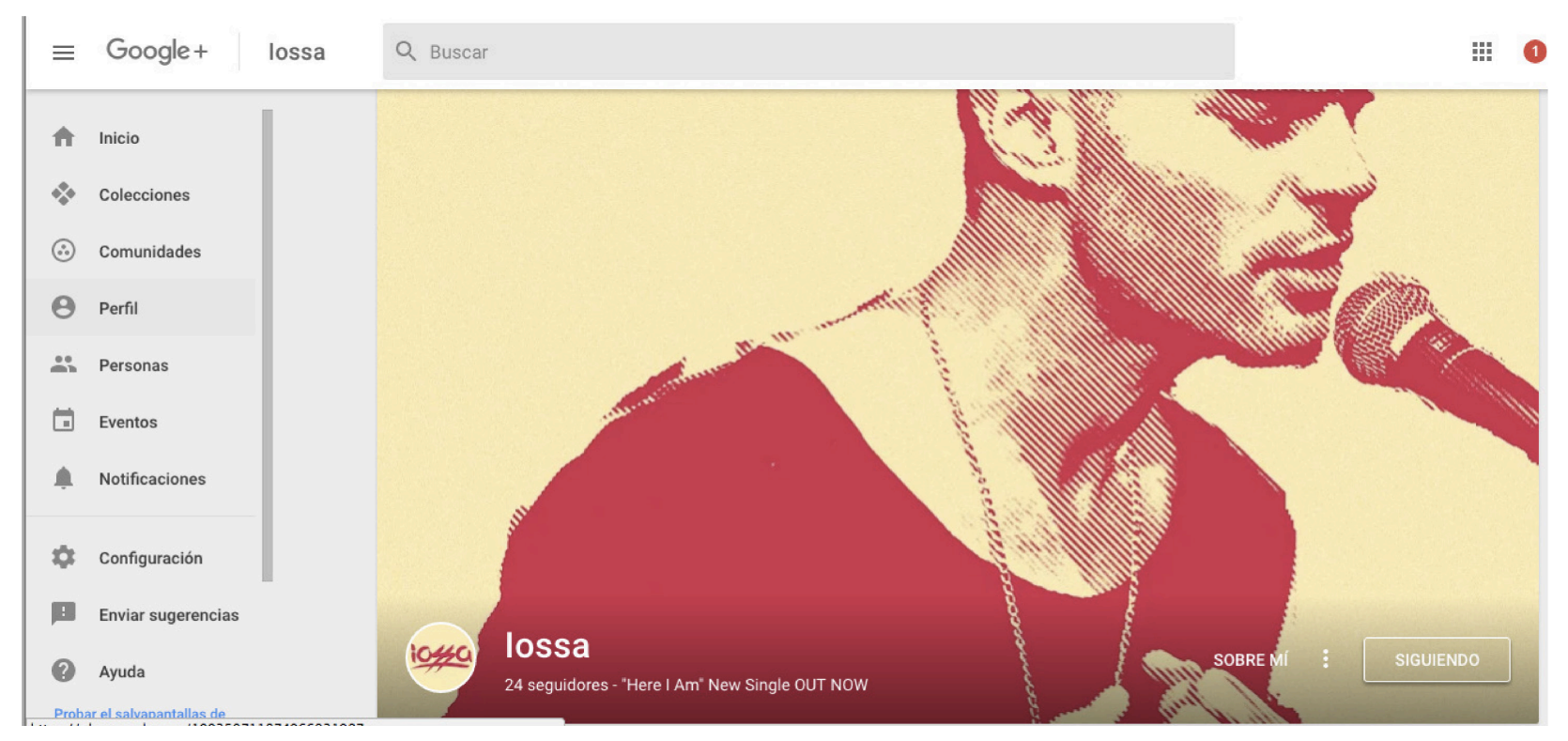

Figura 23.- Google+ IOSSA

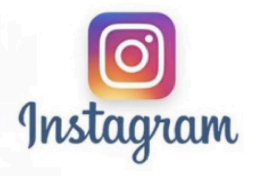

Con 4.200 millones de likes diarios, Instagram es una de las redes sociales más importantes de estos tiempos. Sirve para compartir fotos con opciones de agregar filtros, editarlas, etc., de igual manera videos. Se creó una cuenta de Instagram para IOSSA con el fin de compartir momentos de la vida diaria del artista y así generar mayor empatía con sus fans y por lo tanto ganar nuevos fans. Actualmente IOSSA cuenta con 2.462 seguidores $^{48}$.

\footnotetext{
${ }^{48}$ Instagram. (2017). Instagram.com. Retrieved 20 de 02 de 2017 from lossa oficial: https://www.instagram.com/iossaofficial/
} 
(0) Instagram
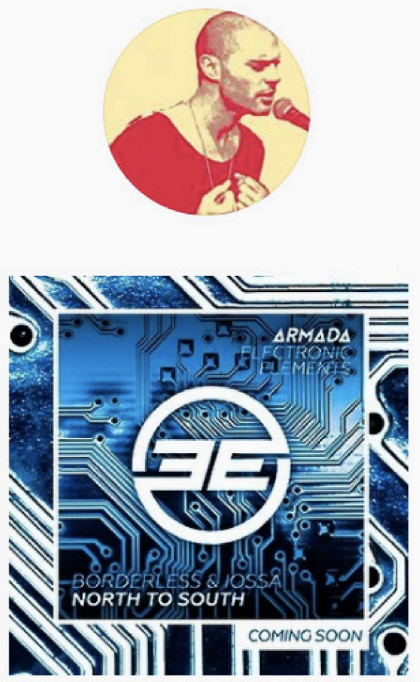

iossaofficial seguir

$\mathbf{5 7 7}$ publicaciones $\quad \mathbf{2 . 4 6 2}$ seguidores $\quad \mathbf{2 8 3}$ seguidos
Figura 24.- Instagram IOSSA
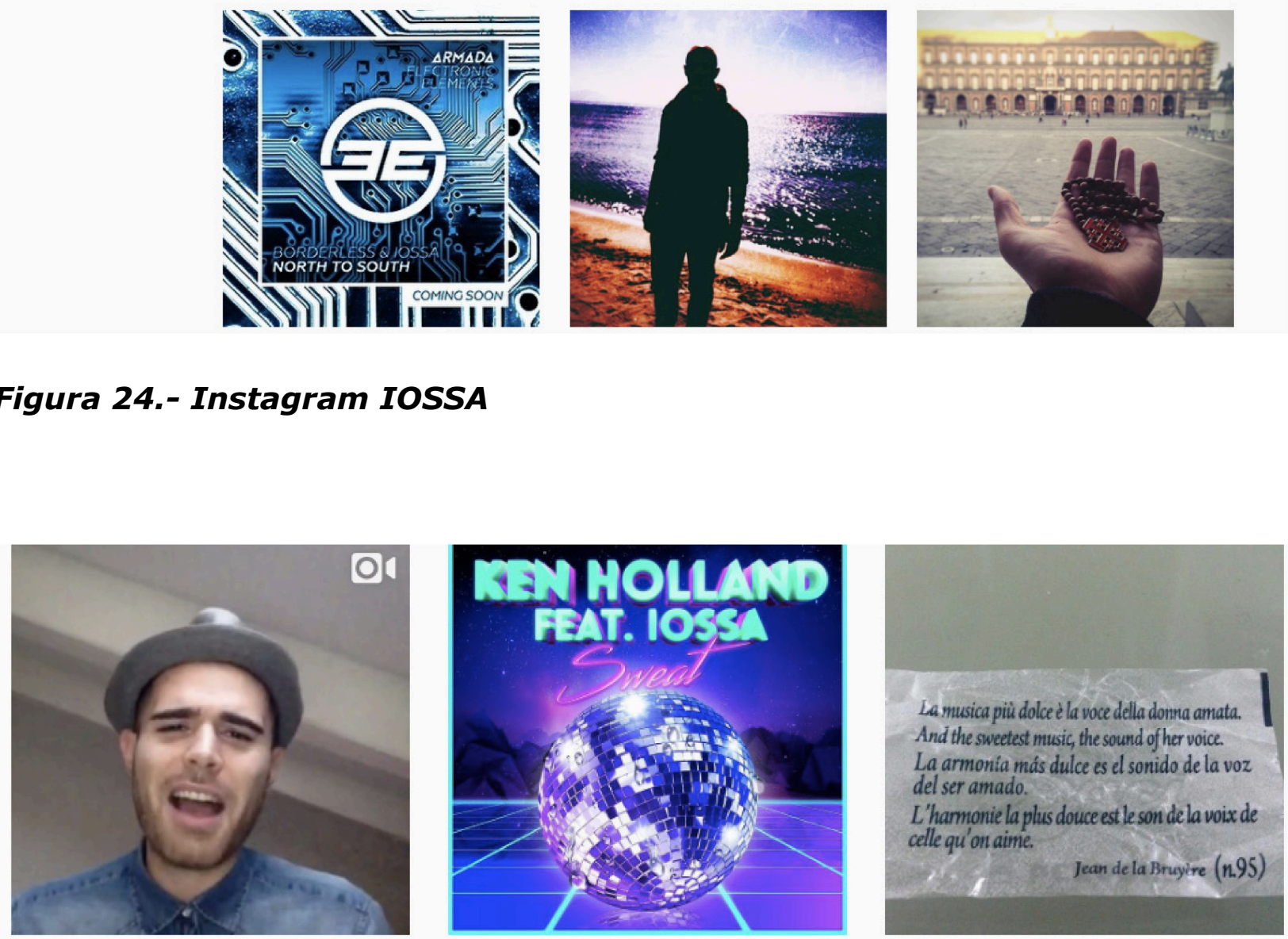
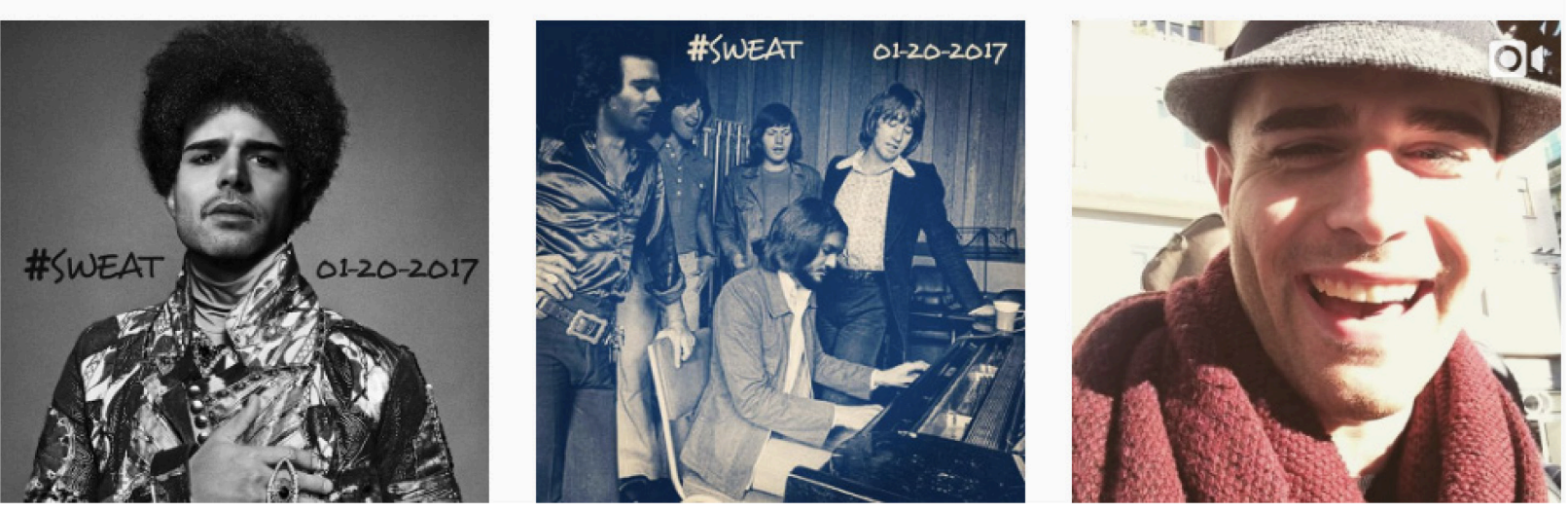

Figura 25.- Instagram videos IOSSA 


\section{You Tube}

Con 1.000 millones de usuarios, Youtube es un portal en el cuál se pueden mirar videos gratuitos, ya sea de música o inclusive académicos. Para la Agencia fue muy importante crear el canal de Youtube para IOSSA debido a que es una forma de promocionar su música gratuitamente y llegar a más usuarios. En el canal de IOSSA se pueden observar varios videos en los cuales están plasmados el talento del artista ${ }^{49}$.

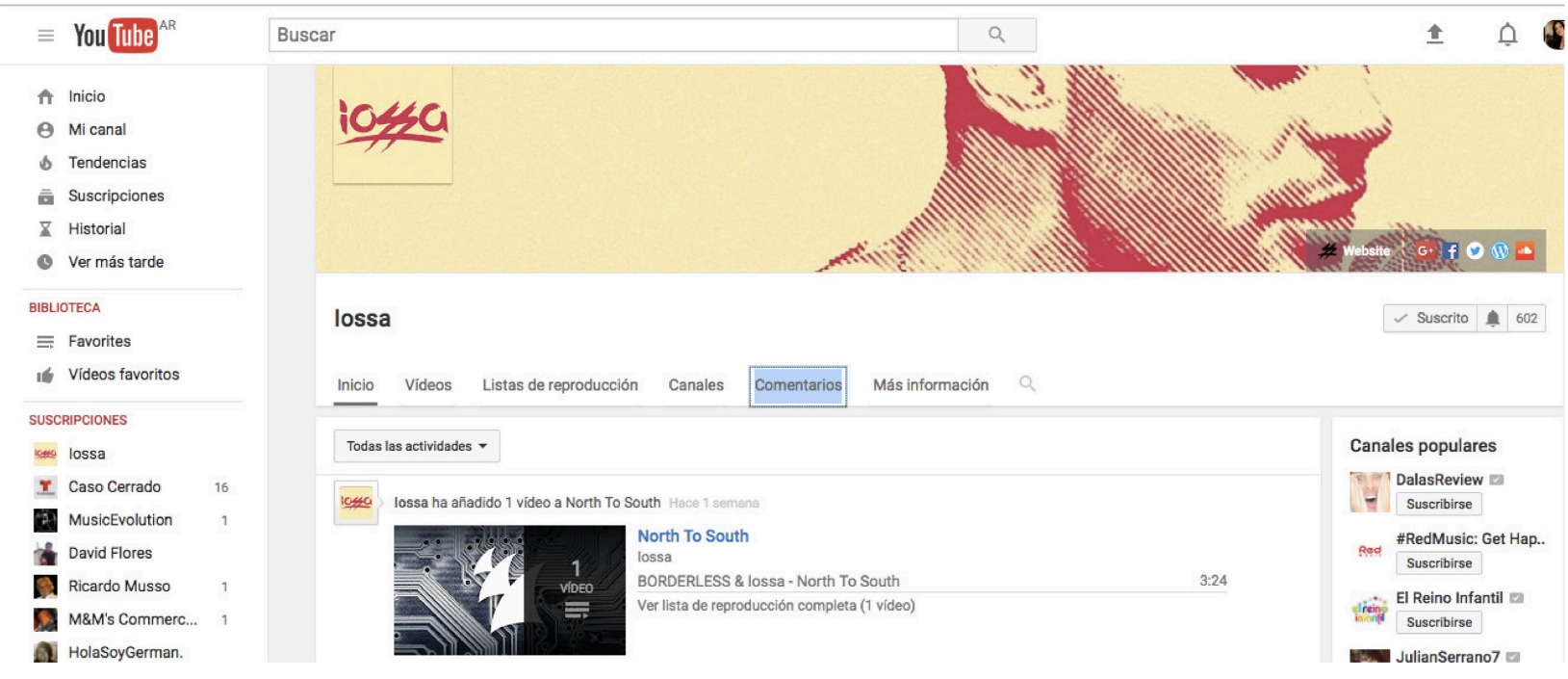

Figura 26.- Youtube IOSSA

${ }^{49}$ Youtube. (2017). Youtube.com. Retrieved 02 de 02 de 2017 from lossa oficial: https://www.youtube.com/c/iossaofficial 


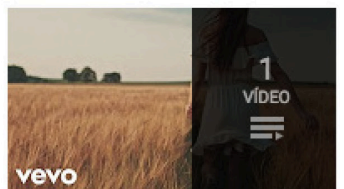

Iossa ha añadido 1 video a Leap Of Faith Hace 1 año

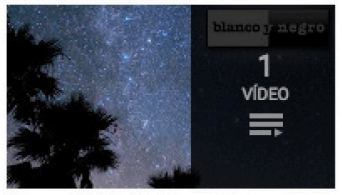

Leap Of Faith

lossa

Max Zotti Feat. lossa - Leap Of Faith (Official Lyric Video)

Ver lista de reproducción completa (1 video)

lossa ha subido un vídeo Haç 1 aกิ๊

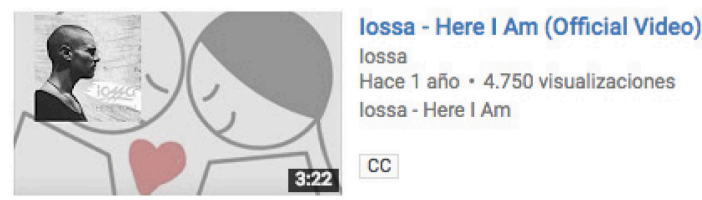

Figura 27.- Youtube videos IOSSA

\section{Linkedin.}

Linkedin, es una red profesional en la cual se encuentra el perfil profesional de sus usuarios. Para IOSSA se creó un perfil en esta red social, para mostrar presencia y perfil profesional ${ }^{50}$.

${ }^{50}$ Linkedin. (2017). Linkedin.com. Retrieved 20 de 02 de 2017 from lossa oficial: https://www.linkedin.com/in/iossaofficial/ 


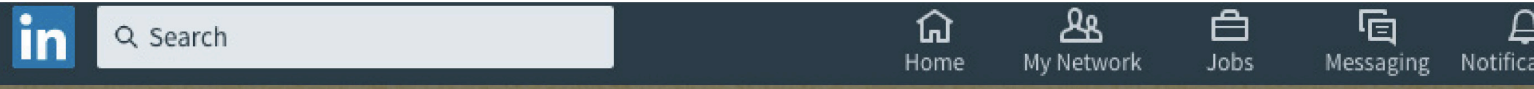

Masters In Publlc Health - Advance your career Berkeley Onlline MPH In Global Health. Apply n

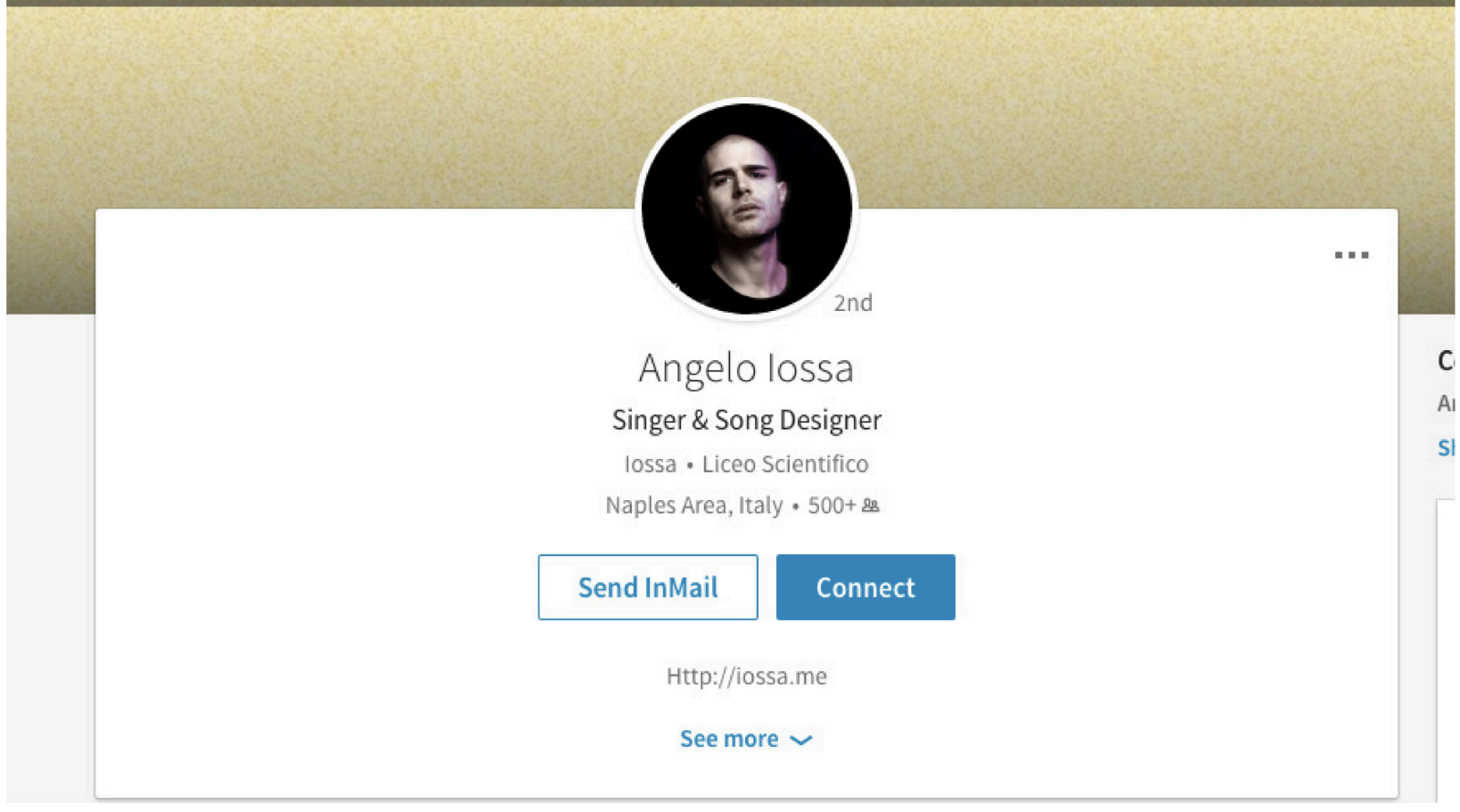

Figura 28.- Linkedin IOSSA

\section{VK, Vkontakte}

VK, es una red social europea en 400 millones de usuarios pero 90 activos. Se creó un perfil para esta red social pero no se enfatizó mucho en la promoción debido a que IOSSA no cuenta con tantos seguidores por la popularidad de la página ${ }^{51}$.

${ }^{51}$ Vk. (2017). Vk. Retrieved 20 de 02 de 2017 from lossa oficial: https://vk.com/iossaofficial 


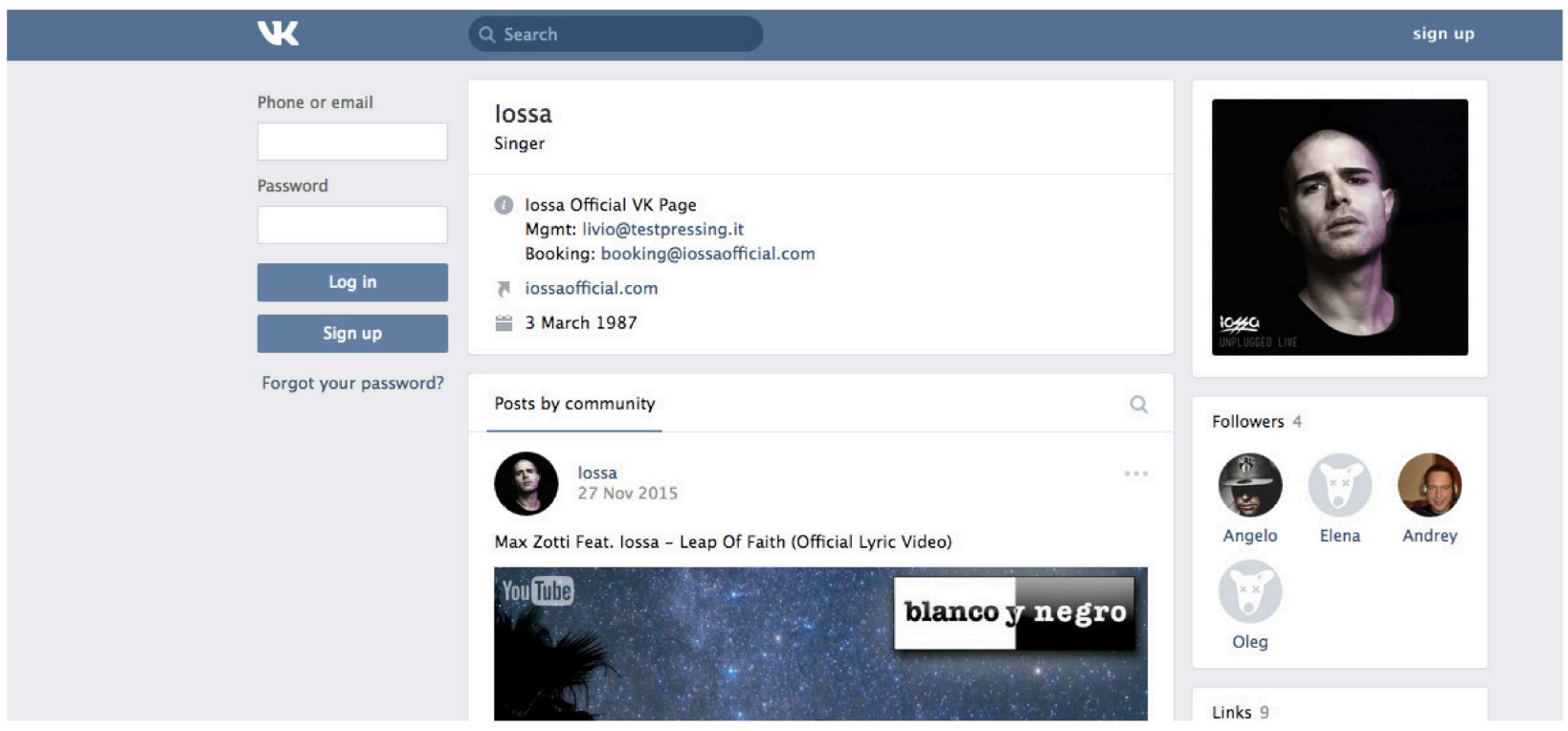

Figura 29.- VK IOSSA

PORTALES DE MUSICA EN STREAMING

https://itunes.apple.com/it/artist/iossa/id517491723

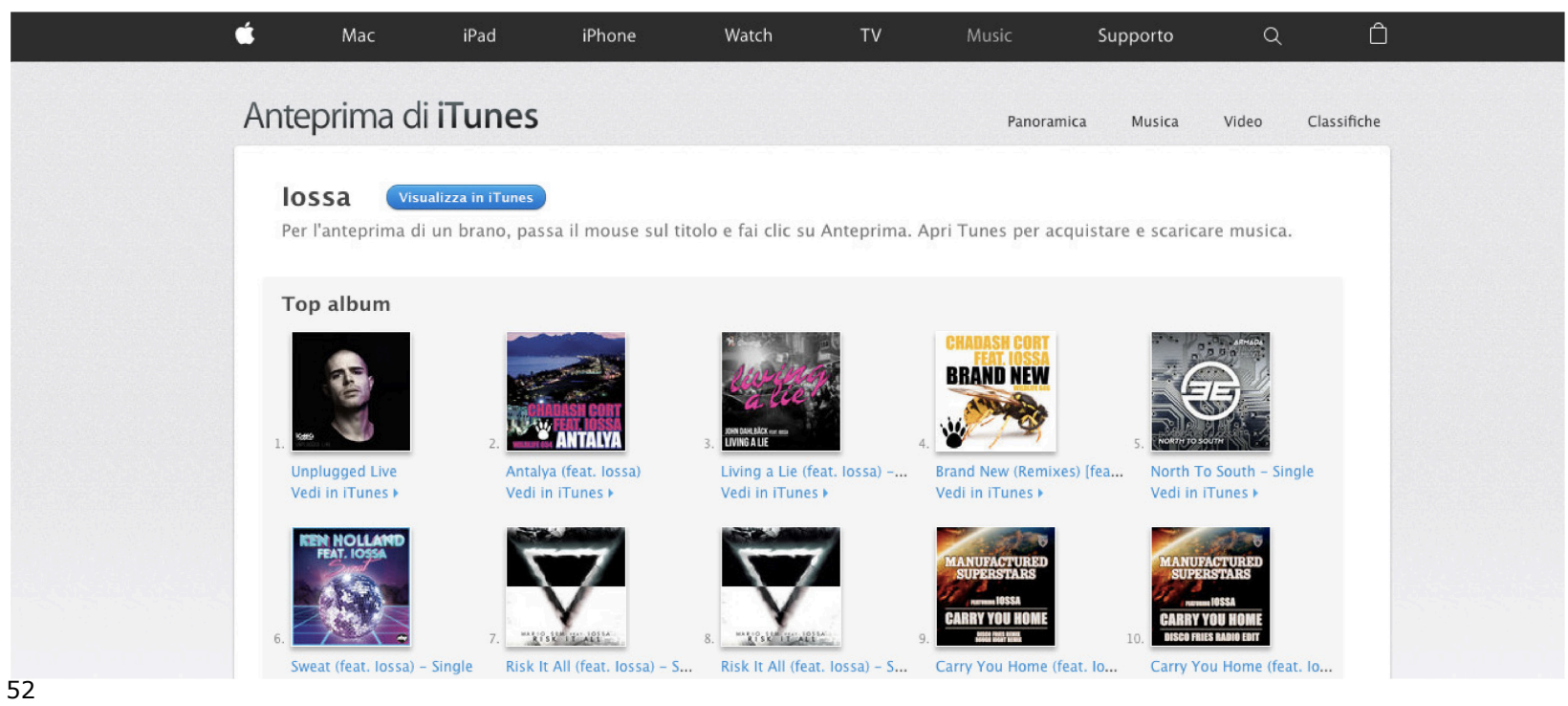

Figura 30.- itunes IOSSA

52 itunes. (2016). itunes.com. Retrieved 20 de 02 de 2017 from lossa:

https://itunes.apple.com/it/artist/iossa/id517491723 


\section{§spotify}

Iniciar sesión para escuchar gratis

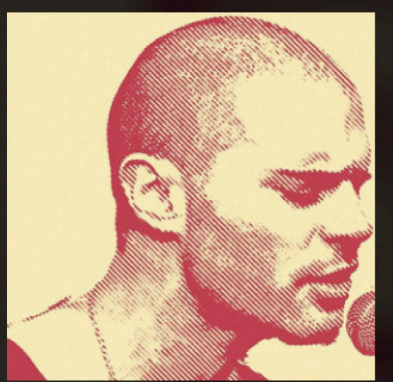

REGISTRARTE CON FACEBOOK

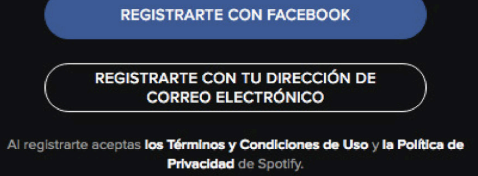

Privacldad de Spotify

¿Ya tlenes cuenta? Inicla sesión aqui.

lossa

Figura 31.- Spotify IOSSA

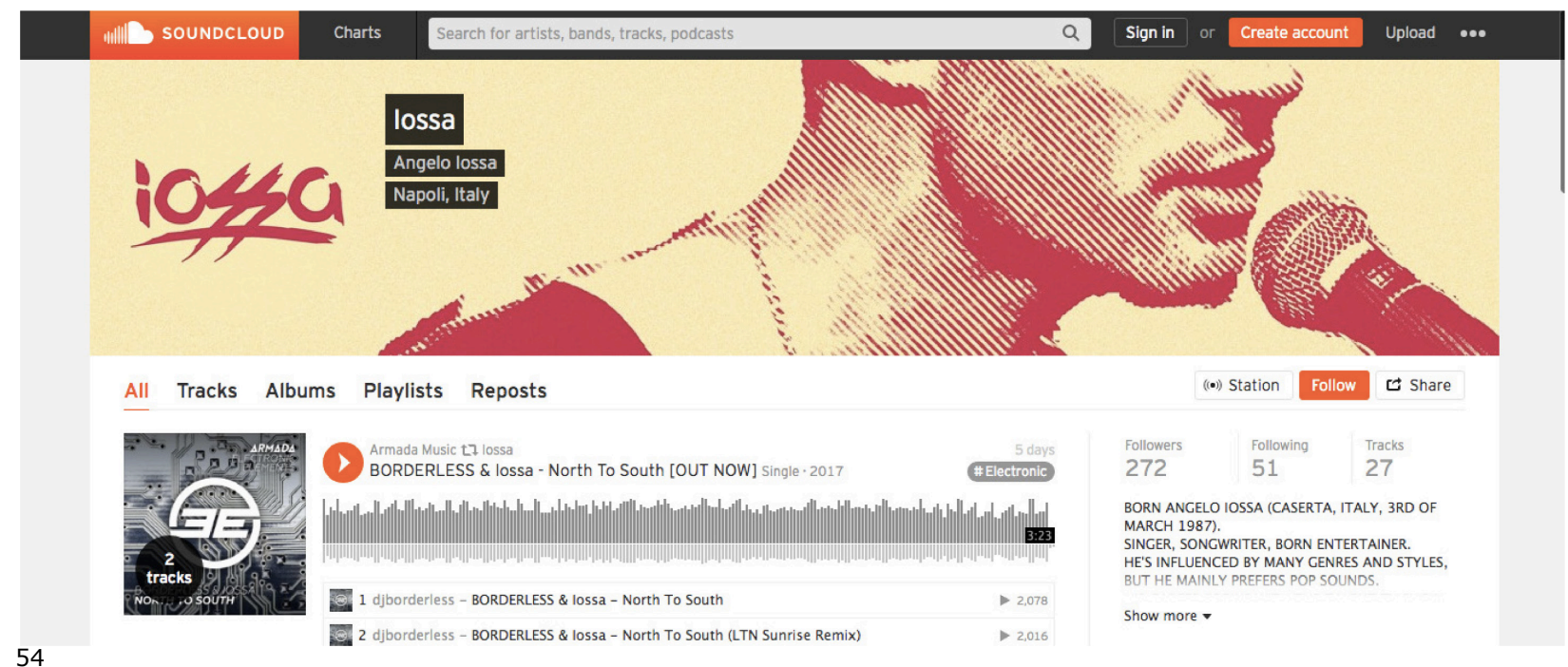

Figura 32.- SoundCloud IOSSA

\subsubsection{Estrategias a futuro}

- Se pensó promocionar internacionalmente su carrera musical, empezando en Argentina debido al impacto que puede tener en América latina.

\footnotetext{
${ }^{53}$ Spotify. (2017). Spotify.com. Retrieved 20 de 02 de 2017 from lossa: https://play.spotify.com/artist/2AczWWagD4DfWLfJVASu5r

${ }^{54}$ Sound Cloud. (2016). Soundcloud.com. Retrieved 20 de 02 de 2017 from lossa: https://soundcloud.com/iossaofficial
} 
- Promocionar la página Web de IOSSA para que se encuentre dentro de los primeros lugares de Google (SEO/SEM).

- Seguir con las campañas de Redes Sociales, en las que se promociona la carrera de IOSSA a nivel internacional, especialmente para el país que se piensa promocionar.

- Buscar Alianzas estratégicas con nuevos productos/marcas para que IOSSA use en sus videos o presentaciones y a la vez promocione las marcas.

- Tratar de ganar contratos para presentaciones tanto en eventos públicos importantes, como en eventos privados y publicitarlos a gran escala.

- Lograr invitaciones a IOSSA a entrevistas en radios que son las más escuchadas por el target objetivo.

- Generar espacios en los cuáles los fans puedan tener un contacto directo con IOSSA para tomarse fotos o firmar autógrafos. 


\section{Conclusiones.}

- La creación de una Agencia de Representación de Artistas musicales como un plan de negocio, no solo fue de gran utilidad académica principalmente para la obtención del título de postgrado de marketing internacional pero también muy útil para obtener experiencia en el medio al trabajar en un caso real en que se aplicaron los conocimientos adquiridos.

- En primera instancia se planteó a MUSIKK como una empresa nueva con una idea de negocio que no necesita mucha inversión económica, y que a su vez sus puntos fuertes y sus puntos débiles se los trabajará para garantizar el éxito de la misma.

- Al analizar la situación general del mercado, se pudo observar que existen tendencias dar a conocer la música de nuevos artistas por medio de Redes Sociales y así abarcar mayor audiencia con menores costos.

- Se pudo identificar como la principal competencia para la agencia de representación a los mismos artistas que al tener acceso a las redes sociales, pueden mostrar su talento y de esta forma buscar el éxito sin pensar que por medio de un agente de representación puede llegar a hacerlo más profesional.

- Se puede concluir que para la creación de MUSIKK, no se necesita una gran inversión económica debido a que la mayoría de funciones de la empresa se las trabajarán de forma digital y remota por lo que se abarataron costos y con la proyección de obtener mayores ganancias y poderlas reinvertir en la empresa.

- MUSIKK a comparación de las grandes agencias de representación que ya están posicionadas en el mercado, recién está en una etapa de introducción en la cual se manejará de manera remota para poder captar nuevos talentos y usará a las grandes agencias como intermediarias para obtener nuevos contratos para sus clientes.

- En los mapas de posicionamiento se tomaron a distintos artistas famosos de los cuáles se usaron como ejemplo para aplicar ciertas estrategias de marketing para IOSSA, una de ellas es de Richard Ashcroft que al ser un músico con un estilo de baladas rock, incursionó en el género dance con una mezcla de rock + electrónica, caso que se recomendó a IOSSA y lo cumplió con éxito. 
- Se pudo observar que uno de los principales desafíos que tendrá MUSIKK es la captación de nuevos artistas, por lo que se deberá trabajar en profundidad con la promoción de los servicios que ofrece la empresa y así poder cumplir con las ventas proyectadas.

- Realizar esta tesina fue de gran utilidad para reforzar los conocimientos adquiridos durante la maestría y ponerlos en práctica en una idea de negocio con gran potencial. 


\section{Bibliografía}

Libros

Álvaro, F. V. (2007). Aprender a elaborar un plan de negocios (Paidós ed.). Barcelona.

Alet, J. (2011). Marketing directo e interactivo. Campañas efectivas con sus clientes.

Segunda edición. Madrid: Esic Editorial.

Amaya, C. (2011). Mercadotecnia para proyectos artísticos. Createspace.

Bahanovich, D., \& Collopy, D. (2009). Music experience and behaviour in young people (University of Herpordshire ed.). UK.

Bradley, F. Marketing Internacional 5ta Edición. Editorial Pearson - Prentice Hall.

Colbert, F., Cuadrado, M., Nantel, J., Bilodeau, S., Rich, J. D., \& De Montoro, J. (2009).

Marketing de las Artes y la Cultura. 4ta Impresión. Barcelona: Ariel S.A.

Gilmore, J. H., \& Pine II, B. J. (2009). Marketing $1 \times 1$ cada cliente es un mercado. Harvard Business Review. Bogotá: Grupo Editorial Norma.

Harvard Business School Publising Corporation. (2009). Plan de negocios. Santiago Chile: Impact Media Comercial S.A.

King, M. (2009). Music Marketing. Boston: Berklee Press.

Kotler, P., \& Amstrong, G. (Sexta Edición). Fundamento de Marketing. Ciudad de México: Pearson Educación.

Lathrop, T. (2013). This Business of global music marketing. New York: Watson - Guptill Publications.

Lerma Kirchner, A. E., \& Márquez Castro, E. (2010). Comercio y marketing internacional. Cuarta edición. México, D.F.: Cengage Learning.

Martín, D. A. (2011). Marketing Musical. Música industrial y promoción en la era digital. (C. Commons, Ed.) 
Morales, D. V. (2014). Innovación y marketing de servicios en la era digital. Madrid: Esic Editorial.

Riesco, J. L. (2011). Comercio Internacional cuarta edición. Madrid: Esic Editorial.

Rosal, A. N. (15 de enero de 2015). El Rock sigue siendo el género más popular en los Estados Unidos. Retrieved 2017 de Febrero de 13 from industriamusical.es:

http://industriamusical.es/el-rock-sigue-siendo-el-genero-mas-popular-en-los-estados-unidos/

Sanna, D. (2013). Comunicación rentable en marketing. Seis pasos en la era de las redes sociales. Buenos Aires: Marcom Ediciones.

Terragno, L. D., \& Lecuona, M. (1999). Cómo armar un plan de negocios. Capital Federal, Argentina: Editorial Coyuntura SAC.

Viejo, L. C. (2014). Plan de informes de marketing internacional. España: Ediciones Paraninfo S.A.

Fuentes de Internet

Compositores, C. i. (2015). CISAC. Retrieved 31 de enero de 2017 from cisac.org: http://es.cisac.org/Sala-de-prensa/Comunicado-de-prensa/Los-derechos-mundialesrecaudados-para-los-creadores-alcanzan-un-record-de-8.600-millones-de-euros Emprendedor XXI Argentina. (2011). Poner en marcha una empresa paso a paso. Retrieved 06 de febrero de 2017 from www.emprendedorxxi.coop:

http://www.emprendedorxxi.coop/html/creacion/creacion_pasos.asp

Emprendedor XXI en Argentina. (2011). Creación de empresas. Retrieved 06 de febrero de 2017 from www.emprendedorxxi.coop:

http://www.emprendedorxxi.coop/html/creacion/creacion_formas.asp

Facebook. (2017). Facebook.com. Retrieved 20 de 02 de 2017 from lossa oficial: https://www.facebook.com/iossaofficial

Google+. (2017). Google+.com. Retrieved 20 de 02 de 2017 from +lossa oficial: https://plus.google.com/+iossaofficial 
Ifpi.org. (abril de 2016). Global Music Report. Retrieved 16 de 02 de 2017 from www.ifpi.org: http://www.ifpi.org/recording-industry-in-numbers.php

Instagram. (2017). Instagram.com. Retrieved 20 de 02 de 2017 from lossa oficial: https://www.instagram.com/iossaofficial/

IOSSA. (2015). Iossa oficial. Retrieved 25 de 01 de 2017 from lossa oficial:

http://www.iossaofficial.com/

Ipsos Connect. (2016 de 09 de 2016). Music consumer insight report. Retrieved 14 de 02 de 2017 from ifpi.org: http://www.ifpi.org/news/IFPI-and-Ipsos-publish-Music-Consumer-InsightReport-2016

itunes. (2016). itunes.com. Retrieved 20 de 02 de 2017 from lossa:

https://itunes.apple.com/it/artist/iossa/id517491723

Linkedin. (2017). Linkedin.com. Retrieved 20 de 02 de 2017 from lossa oficial:

https://www.linkedin.com/in/iossaofficial/

Sound Cloud. (2016). Soundcloud.com. Retrieved 20 de 02 de 2017 from lossa:

https://soundcloud.com/iossaofficial

Spotify. (2017). Spotify.com. Retrieved 20 de 02 de 2017 from lossa:

https://play.spotify.com/artist/2AczWWagD4DfWLfJVASu5r

Twitter. (2017). Twitter.com. Retrieved 20 de 02 de 2017 from lossa oficial:

https://twitter.com/iossaofficial

United Nations International Telecommunications Union. (2016). UN News Centre. Retrieved 21 de Julio de 2016 from Copyright United Nations:

http://www.un.org/apps/news/story.asp?NewsID=47729\#.V5VhLTm7iko

Vk. (2017). Vk. Retrieved 20 de 02 de 2017 from lossa oficial: https://vk.com/iossaofficial

Worlwide independent network. (2016). Investinginmusic.ifpi.org. (IFPI, Editor) Retrieved 15 de 02 de 2017 from www.ifpi.org: http://investinginmusic.ifpi.org/

Youtube. (2017). Youtube.com. Retrieved 02 de 02 de 2017 from lossa oficial:

https://www.youtube.com/c/iossaofficial 


\section{Entrevista}

Bilbao, P. (26 de Febrero de 2017). Representación de músicos en crecimiento. (M. J. Ávalos, Entrevistador) 
"Declaro bajo juramento que esta tesis fue elaborada por mí, que no utilicé ningún otro material que no haya dado a conocer en las referencias y que no utilicé frases o párrafos de otros autores y que este trabajo de tesis nunca ha sido presentado ante un comité de evaluación de tesis y que no transgrede derechos de terceros."

María José Ávalos Ledesma 
